Universidade de São Paulo

Escola Superior de Agricultura "Luiz de Queiroz"

A radiação fotossinteticamente ativa no manejo florestal otimiza o crescimento de vegetação sob plantios de eucalipto

\title{
Leonardo Tardivo
}

Dissertação apresentada para obtenção do título de Mestre em Ciências, Programa: Recursos Florestais.

Opção em: Tecnologia de Produtos Florestais

Piracicaba 


\title{
Leonardo Tardivo \\ Engenheiro Agrônomo
}

A radiação fotossinteticamente ativa no manejo florestal otimiza o crescimento de vegetação sob plantios de eucalipto

versão revisada de acordo com a resolução CoPGr 6018 de 2011

\author{
Orientador: \\ Prof. Dr. JOSÉ NIVALDO GARCIA
}

Dissertação apresentada para obtenção do título de Mestre em Ciências, Programa: Recursos Florestais.

Opção em: Tecnologia de Produtos Florestais 
Dados Internacionais de Catalogação na Publicação DIVISÃO DE BIBLIOTECA - DIBD/ESALQ/USP

Tardivo, Leonardo

A radiação fotossinteticamente ativa no manejo florestal otimiza o crescimento de vegetação sob plantios de eucalipto / Leonardo Tardivo. - versão revisada de acordo com a resolução CoPGr 6018 de 2011.

Piracicaba, 2017.

$62 \mathrm{p}$.

Dissertação (Mestrado) - - USP / Escola Superior de Agricultura "Luiz de Queiroz".

1. Radiação fotossinteticamente ativa 2. Eucalipto 3. Manejo florestal 4. Sistemas agroflorestais. I. Título 


\section{DEDICATÓRIA}

À Deus, não para nós Senhor, não para nós, mas para a Glória do teu Nome.

À minha esposa Liliane pelo apoio e paciência durante esses anos de dedicação a ciência.

À minha família, aos que estão presentes, aos que já se foram e aos que estão por vir.

À ciência que busca incessantemente devendar os mistérios de Deus.

Dedico

À todos que de alguma forma contribuiram para meu trabalho.

Amigos, professores e funcionários.

Ofereço 


\section{AGRADECIMENTOS}

À Fundação CAPES pela bolsa de mestrado a mim outorgada.

Ao meu Orientador Professor José Nivaldo Garcia que me apoiou na iniciativa de estudar a radiação e a orientação dada.

Ao Professor Ciro Abbud Righi, pela experiência passada e pelo empréstimo do aparelho utilizado neste trabalho.

Ao Professor Paulo César Sentelhas, pelo tempo dedicado ao esclarecimento de dúvidas.

Ào meu mentor e amigo Professor Valdemar Antonio Demétrio, pela disposição em ajudar na correção deste trabalho e pela permissão de usar sua área para realização de experimentos. Também ao Maciel, funcionário do sítio.

À produtora rural e amiga Marina Goreti Sandin, pela permissão de usar sua área para a realização de experimentos.

Aos colegas de mestrado Júlia Fideles e Lucas Kelvin, por partilharem comigo a mesma caminhada, pelo apoio nas matérias e na execução dos experimentos.

Aos meus escudeiros da graduação Otávio Oliveira, Vinicius Felipe Momo e Jaqueline Morales, por escutarem o pouco que tenho para ensinar e pela ajuda na coleta de dados dos experimentos.

Às Estações Experimentais de Ciências Florestais de Anhembi e Itatinga representados pelos Engenheiros floretais João Carlos Teixeira Mendes e Rildo Moreira e Moreira, pelas informações prestadas e permissão para realizar os experimentos nelas.

Ao Laboratório de Propriedades Físicas e Processamento da Madeira, ao Técnico Luis Eduardo Facco, aos orientados de graduação e pós graduação.

Ao Professor Fernando Seixas, ao Sílvio José Gerolamo e ao Mauro Rasera, pelo apoio da atividade extra-curricular de Esgrima Medieval na Atlética da ESALQ.

Aos docentes, funcionários e apoiadores da Pós-graduação de Recursos Florestais.

Aos funcionários do departamento de Recursos Florestais e Laboratório de Ecologia Aplicada, agradecimento especial a Lucilene C. Saldanha.

À empresa RNT Consultoria, pela oportunidade de experiência profissional.

Ao Grupo de Estágio Monte Olimpo pelas informações prestadas a respeito de seus experimentos. 
Certa vez perguntaram a Einstein sobre a definição da luz e ele respondeu:

"A luz... é a sombra de Deus...".

Albert Einstein 


\section{SUMÁRIO}

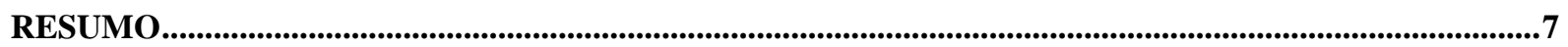

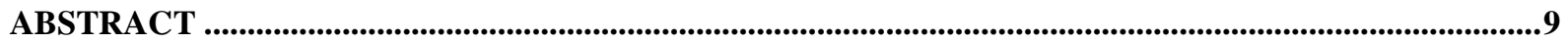

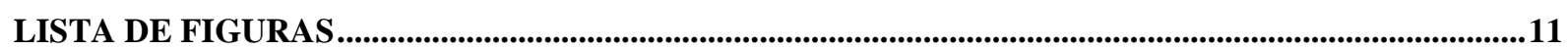

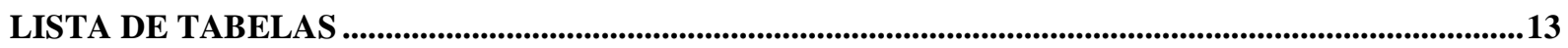

LISTA DE ABREVIATURAS E SIGLAS .............................................................................................................14

1. INTRODUÇÃ

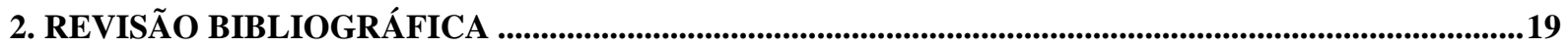

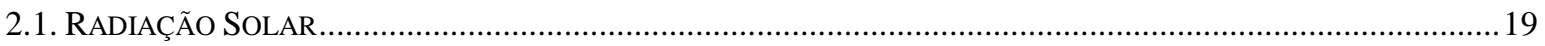

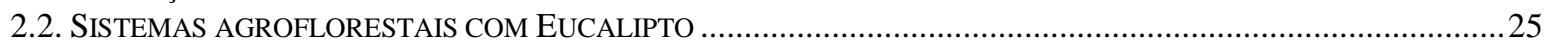

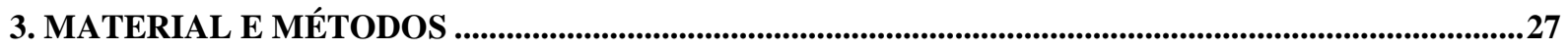

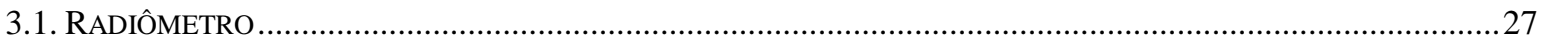

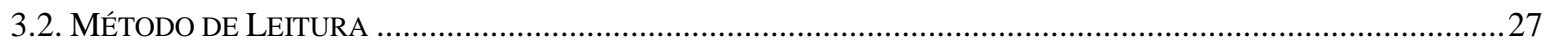

3.3. CÁLCULO DO ÍNDICE DE ÁREA FOLIAR ATRAVÉS DA RADIAÇÃo FOTOSSINTETICAMENTE ATIVA ...............29

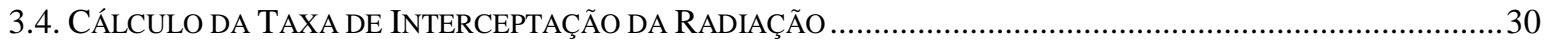

3.5. CRITÉRIO DE CATEGORIZAÇÃO PARA O DESENVOLVIMENTO DE PLANTAS NAS LINHAS E ENTRELINHAS DOS

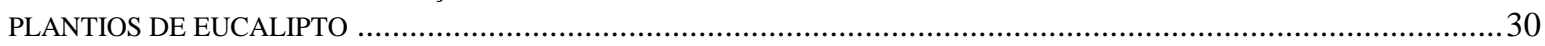

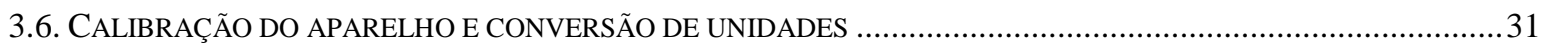

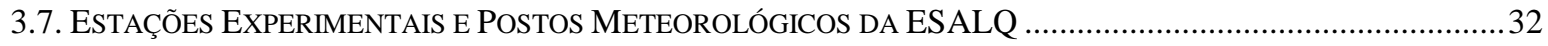

3.8. EXPERIMENTO DE AVALIAÇÃO DE FILEIRA DUPLA ISOLADA BAIRRO FLORESTA, PIRACICABA-SP ..............32

3.9. EXPERIMENTO DE COMPARAÇÃO ENTRE ESPÉCIES NO BAIRRO ÁGUA BONITA, PIRACICABA-SP..................33

3.10. EXPERIMENTO DE AVALIAÇÃO DE DESRAMA NO BAIRRO ÁGUA BONITA, PIRACICABA-SP .......................37

3.11. EXPERIMENTO DE COMPARAÇÃO ENTRE INTENSIDADES DE DESBASTE NA EECFI, ITATINGA-SP...............38

3.12. EXPERIMENTO DE COMPARAÇÃO ENTRE ESPÉCIES NA EECFA, ANHEMBI-SP ......................................39

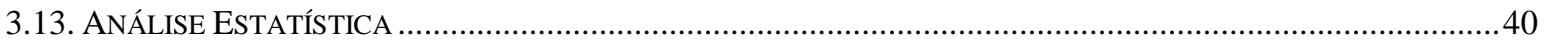

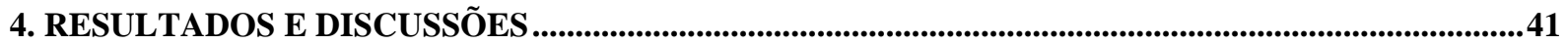

4.1. EXPERIMENTO DE AVALIAÇÃO DE FILEIRA DUPLA ISOLADA NO BAIRRO FLORESTA, PIRACICABA-SP:........41

4.2. EXPERIMENTO DE COMPARAÇÃO ENTRE ESPÉCIES NO BAIRRO ÁGUA BONITA, PIRACICABA-SP: ...............41

4.3. EXPERIMENTO DE AVALIAÇÃO DE DESRAMA NO BAIRRO ÁGUA BONITA, PIRACICABA-SP:........................46

4.4. EXPERIMENTO DE COMPARAÇÃO ENTRE INTENSIDADES DE DESBASTE NA EECFI, ITATINGA-SP:..............49

4.5. EXPERIMENTO DE COMPARAÇÃO ENTRE ESPÉCIES NA EECFA, ANHEMBI-SP:......................................50

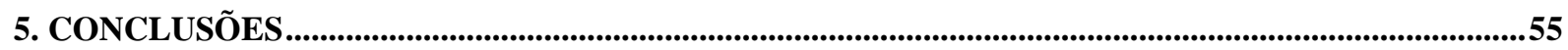

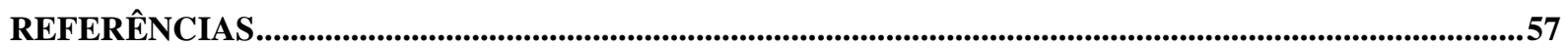




\title{
RESUMO
}

\section{A radiação fotossinteticamente ativa no manejo florestal otimiza o crescimento de}

\author{
vegetação sob plantios de eucalipto
}

A radiação fotossinteticamente ativa (RFA) é uma das variáveis mais importantes para o crescimento e desenvolvimento de plantas, estejam elas localizadas, na terra, abaixo da água ou no espaço sideral. Quando se trata de sistemas agroflorestais a RFA é uma das variáveis mais importantes, por isso nesses sistemas existe a necessidade de criar na floresta as melhores condições para o desenvolvimento das culturas abaixo desta. Condições essas dependentes da escolha da espécie, do espaçamento e dos manejos silviculturais, refletindo diretamente na radiação disponível abaixo da floresta. Em pequenas propriedades rurais o eucalipto vêm sendo utilizado como um cultivo secundário à agricultura e por se tratar de uma cultura de longo prazo o cultivo do eucalipto enfrenta dificuldades em sua permanência nessas pequenas propriedades. Uma das alternativas é o seu uso em sistemas agroflorestais, de forma que se mantenha a produção agrícola e ao mesmo tempo a floresta de eucalipto. Este trabalho teve como objetivo estudar diferentes situações de plantios de eucalipto já estabelecidos e sua relação com a RFA, e através dela obter para os eucaliptos a Taxa de interceptação (TI) e Indice de área foliar (IAF) pela Lei de Lambert-Beer. Neste trabalho foram avaliados plantios de eucalipto tendo como variáveis: espécies e as práticas de manejo de desrama e desbaste contemplando os seguintes experimentos e resultados: Avaliação de fileira dupla isolada com espaçamento $3 \times 2 \mathrm{~m}$, com E. urophylla $\times E$. grandis com 24 meses de idade (Piracicaba-SP) em que fileiras duplas apresentaram de condições RFA razoáveis nas entrelinhas (200 e $799 \mu_{\mathrm{mol} \mathrm{m}}^{-2} \mathrm{~s}^{-1}$ ) e ideal nas linhas (maior que $800 \mu \mathrm{mol} \mathrm{m}^{-2} \mathrm{~s}^{-1}$ ) para o desenvolvimento de plantas nas entrelinhas e melhor nas linhas; Comparativo entre espécies de eucalipto com 60 meses de idade e espaçamento $3 \times 2 \mathrm{~m}$ (Piracicaba-SP) em que nas entrelinhas as espécies $E$. camaldulensis, $E$. robusta, E. grandis, IPEF 137, E. urophylla $\times$ E. grandis, E. urophylla e E. saligna e nas as linhas E. camaldulensis, E. robusta, E. grandis, E. urophylla $\times$ E. grandis e E. saligna apresentaram condições razoáveis de RFA para o desenvolvimento de plantas; Comparativo entre antes e depois da desrama em 7 espécies de eucalipto com 12 meses de idade e espaçamento $3 \times 2$ m (Piracicaba-SP) onde houve aumento da RFA depois da desrama na maioria dos casos, antes da desrama nas entrelinhas apenas as espécies $\mathrm{H} 15$ e E. grandis apresentaram condições razoáveis de RFA para o desenvolvimento de plantas, depois da desrama as espécies H15, 1144 e E. grandis, E. urophylla e E. citriodora apresentaram essas condições, nas linhas antes da desrama nenhuma das espécies apresentaram condições razoáveis de RFA, depois da desrama as espécies I144, H13, E. urophylla e E. citriodora apresentaram condições razoáveis de RFA para o desenvolvimento de plantas; Comparativo entre três intensidades de desbaste, 55\%, 70\% e 85\%, em eucalipto $E$. grandis com 228 meses de idade e espaçamento original $3 \times 2 \mathrm{~m}$ (Itatinga-SP) em que todas as intensidades apresentaram condições razoáveis de RFA para o desenvolvimento de plantas, sendo os melhores resultados obtidos nas linhas e entrelinhas da intensidade de 70\%; Comparativo entre 24 espécies de eucalipto com 12 meses de idade e espaçamento $3 \times 2 \mathrm{~m}$ (Anhembi-SP) cujos resultados nas entrelinhas as espécies E. citriodora, E. pilularis, E. phaeothrica, E. microcorys, E. deglupta, E. paniculata, E. tereticornis, E. exserta, E. saligna, E. botryoides, E. grandis, E. 
urophylla, E. urophylla x E. grandis, E. pellita, E. propinqua, E. resinifera, E. dunni, E. robusta e $E$. camaldulensis apresentaram condições razoáveis de RFA e as espécies $E$. maculata, E.torelliodora e E. cloeziana apresentaram condições ideais de RFA para o desenvolvimento de plantas, nas linhas as espécies E. citriodora, E. pilularis, E. phaeothrica, E. microcorys, E. deglupta, E. paniculata, E. tereticornis, E. exserta, E. saligna, E. grandis, E. urophylla, E. urophylla $x$ E. grandis, E. pellita, E. propinqua, E. resinifera, E. dunni, E. robusta e E. cloeziana apresentaram condições razoáveis de RFA e as espécies E. maculata, E. torelliodora apresentaram condições ideais de RFA para o desenvolvimento de plantas. Conclui-se com esse trabalho que as espécies E. camaldulensis, E. robusta, E. grandis, E. urophylla $\times E$. grandis e $E$. saligna apresentaram condições razoáveis de RFA tanto aos 12 meses como aos 60 meses, porém, somente as espécies E. maculata, E. torelliodora e E. cloeziana com 12 meses apresentaram condições ideais de RFA; o desbaste teve efeito positivo no aumento da RFA com as intensidades de $70 \%$ e $85 \%$ em comparação com a de $55 \%$; plantios de eucalipto em fileira dupla solitária permitem que a RFA seja transmitida pela copa das árvores com maior facilidade nas linhas e menor nas entrelinhas, ambas são favorecidas por não haverem fileiras de árvores em um dos lados. O cálculo do IAF pela Lei de Lambert-Beer permite a identificação dessa importante variável de forma rápida e não destrutiva. A utilização da Lei de Lambert-Beer na maioria dos casos estudados apresentou como resultado valores dentro do específico para o eucalipto 2 a $4,5 \mathrm{~m}^{2} \mathrm{~m}^{-2}$ (Foelkel, 2005).

Palavras-chave: Radiação fotossinteticamente ativa; Eucalipto; Manejo florestal; Sistemas Agroflorestais 


\section{ABSTRACT \\ The photosynthetically active radiation in forest management optimizes the growth of vegetation under Eucalyptus}

The photosynthetically active radiation (PAR) is one of the most important variables for the growth and development of plants, whether they are located on the earth, under water or in outer space. When it comes to agroforestry systems PAR is one of the most important variables, so in these systems there is a need to create in the forest the best conditions for the development of the crops below it. These conditions depend on species selection, spacing and silvicultural management, directly reflecting the available radiation below the forest. In small farmers, eucalyptus has been used as a crop secondary to agriculture and because it is a long-term crop, eucalyptus cultivation faces difficulties in its permanence in these small farmers. One of the alternatives is its use in agroforestry systems, so as to maintain agricultural production and at the same time the eucalyptus forest. The objective of this work was to study different situations of eucalyptus plantations already established and their relationship with PAR, and through it to obtain for eucalyptus the Intercept Rate (IR) and Foliar Area Index (LAI) by Lambert-Beer Law. In this work, eucalyptus plantations were evaluated, with species variables and the practices of weed management and thinning, the following experiments and results were: Evaluation of an isolated double row with $3 \times 2 \mathrm{~m}$ spacing with E. urophylla $\times$ E. grandis 24 months of age (Piracicaba-SP) in which double rows presented reasonable RFA conditions between the lines (200 and 799 $\mu \mathrm{mol} \mathrm{m} \mathrm{m}^{-2} \mathrm{~s}^{-1}$ ) and ideal in the lines (greater than $800 \mu \mathrm{mol} \mathrm{m} \mathrm{m}^{-2}$ ) for the development of plants between the lines and better in the lines; Comparison between eucalyptus species at 60 months of age and spacing $3 \times 2 \mathrm{~m}$ (Piracicaba-SP) in which the species E. camaldulensis, E. robusta, E. grandis, IPEF 137, E. urophylla $\times$ E. grandis, E. urophylla and E. saligna and in the lines E. camaldulensis, E. robusta, E. grandis, E. urophylla $\times$ E. grandis and E. saligna presented reasonable conditions of PAR for the development of plants; Comparison between before and after the pruning in 7 eucalyptus species at 12 months of age and spacing $3 \times 2 \mathrm{~m}$ (Piracicaba-SP) where there was an increase in PAR after the pruning in the majority of cases, before trawling between the lines only the species H15, E. grandis, $E$. urophylla, and E. citriodora exhibited reasonable conditions of PAR for the development of plants. After pruning the species $\mathrm{H} 15, \mathrm{I} 144$ and E. grandis, E. urophylla and E. citriodora presented these conditions, in the lines before the pruning none of the species presented conditions After the pruning, species 1144, H13, E. urophylla and E. citriodora presented reasonable conditions of RFA for the development of plants; Comparison between three intensities of thinning, 55\%, 70\% and 85\%, in eucalyptus E. grandis with 228 months of age and original spacing $3 \times 2 \mathrm{~m}$ (Itatinga-SP), where all intensities presented reasonable conditions of PAR for Development of plants, being the highest result obtained in the lines and between the lines of the intensity of 70\%; Comparison between 24 species of eucalyptus at 12 months of age and spacing $3 \times 2 \mathrm{~m}$ (Anhembi-SP), with results between the lines $E$. citriodora, E. pilularis, E. phaeothrica, E. microcorys, E. deglupta, E. Paniculata, E. tereticornis, E. exserta, E. saligna, E. botryoides, E. grandis, E. urophylla, E. urophylla $x$ E. grandis, E. pellita, E. propinqua, E. resinifera, E. dunni, E. robusta and E. camaldulensis presented reasonable conditions of PAR and the species E. maculata, E.torelliodora and $E$. cloeziana presented ideal conditions of PAR for the development of plants, in the lines the 
species E. citriodora, E. pilularis, E E. pylori, E. microcorys, E. deglupta, E. paniculata, E. tereticornis, E. exserta, E. saligna, E. grandis, E. urophylla, E. urophylla x E. grandis, E. pellita, E. propinqua, E. resinifera, E. dunni, E. robusta and E. cloeziana presented reasonable conditions of RFA and E. maculata and E. torelliodora presented ideal conditions of PAR for the development of plants. It was concluded that E. camaldulensis, E. robusta, E. grandis, $E$. urophylla $\times$ E. grandis and E. saligna presented reasonable conditions of PAR at 12 months and at 60 months. The species E. maculata, E. torelliodora and E. cloeziana at 12 months presented ideal conditions of PAR; The thinning had a positive effect on the increase of PAR with the intensities of $70 \%$ and $85 \%$ compared to that of $55 \%$; Solitary double row eucalyptus plantations allow the PAR to be transmitted through the tree canopy with greater ease in the lines and smaller between the lines, both are favored because there are no rows of trees on one side. The calculation of the IAF by the Lambert-Beer Law allows the identification of this important variable quickly and non-destructively. The use of the Lambert-Beer Law in the majority of the studied cases presented values within the specific for eucalyptus 2 to $4,5 \mathrm{~m}^{2} \mathrm{~m}^{-2}$ (Foelkel, 2005).

Keywords: Photosynthetically active radiation; Eucalyptus; Forest management; Agroforestry system 
FIGURA 1. RADIÔMETRO ELETM COM SENSOR FOTOELÉTRICO ESPECÍFICO DE FRENTE (ESQUERDA) E DE VERSO (DIREITA).

FIGURA 2. EXEMPLIFICAÇÃO DO MÉTODO DE LEITURA PARA OS TODOS OS EXPERIMENTOS COM ESPAÇAMENTO 3 X 2 M.

FIGURA 3. E. UROPHYLLA $X$ E.GRANDIS FILEIRA DUPLA ISOLADA COM ESPAÇAMENTO 3 X 2 M, COBERTURA DO SOLO (ESQUERDA) E VISTA DE FORA (DIREITA) NO BAIRRO FLORESTA EM PIRACICABA-SP.

FIGURA 4. E. CAMALDULENSIS COBERTURA DO SOLO (ESQUERDA) E VISTA DO DOSSEL (DIREITA) NO BAIRRO ÁGUA BONITA EM PIRACICABA-SP.

FIGURA 5. E. ROBUSTA COBERTURA DO SOLO (ESQUERDA) E VISTA DO DOSSEL (DIREITA) NO BAIRRO ÁGUA BONITA EM PIRACICABA-SP.

FIGURA 6. E. TORELLIANA COBERTURA DO SOLO (ESQUERDA) E VISTA DO DOSSEL (DIREITA) NO BAIRRO ÁGUA BONITA EM PIRACICABA-SP.

FIGURA 7. E. UROPHYLLA COBERTURA DO SOLO (ESQUERDA) E VISTA DO DOSSEL (DIREITA) NO BAIRRO ÁGUA BONITA EM PIRACICABA-SP.

FIGURA 8. ESPÉCIES IPEF 137 COBERTURA DO SOLO (ESQUERDA) E VISTA DO DOSSEL (DIREITA) NO BAIRRO ÁGUA BONITA EM PIRACICABA-SP.

FIGURA 9. E. SALIGNA COBERTURA DO SOLO (ESQUERDA) E VISTA DO DOSSEL (DIREITA) NO BAIRRO ÁGUA BONITA EM PIRACICABA-SP.

FIGURA 10. E. PROPINQUA COBERTURA DO SOLO (ESQUERDA) E VISTA DO DOSSEL (DIREITA) NO BAIRRO ÁGUA BONITA EM PIRACICABA-SP.

FIGURA 11. E. GRANDIS COBERTURA DO SOLO (ESQUERDA) E VISTA DO DOSSEL (DIREITA) NO BAIRRO ÁGUA BONITA EM PIRACICABA-SP.

FIGURA 12. E. UROPHYLLA $X$ E.GRANDIS COBERTURA DO SOLO (ESQUERDA) E VISTA DO DOSSEL (DIREITA) NO BAIRRO ÁGUA BONITA EM PIRACICABA-SP.

FIGURA 13. ESPÉCIES ANTES DA DESRAMA (ESQUERDA) E DEPOIS DA DESRAMA (DIREITA) NO BAIRRO ÁGUA BONITA EM PIRACICABA-SP.

FIGURA 14. E. GRANDIS COM GRAU DE DESBASTE DE 55\% NA ESTAÇÃO EXPERIMENTAL DE CIÊNCIAS FLORESTAIS EM ITATINGA-SP.

FIGURA 15. E. GRANDIS COM GRAU DE DESBASTE DE 70\% NA ESTAÇÃO EXPERIMENTAL DE CIÊNCIAS FLORESTAIS EM ITATINGA-SP.

FIGURA 16. E. GRANDIS COM GRAU DE DESBASTE DE 85\% NA ESTAÇÃO EXPERIMENTAL DE CIÊNCIAS FLORESTAIS EM ITATINGA-SP.

FIGURA 17. ÍNDICE DE ÁREA FOLIAR $\left(M^{2} M^{-2}\right)$ NAS ESPÉCIES DE EUCALIPTO, NO BAIRRO ÁGUA BONITA EM PIRACICABA-SP.

FIGURA 18. TAXA DE INTERCEPTAÇÃO (\%) NAS ESPÉCIES DE EUCALIPTO NAS LINHAS E ENTRELINHAS, NO BAIRRO ÁGUA BONITA EM PIRACICABA-SP.

FIGURA 19. RADIAÇÃO FOTOSSINTETICAMENTE ATIVA ( $\mu M O L M^{-2} \mathbf{S}^{-1}$ ) NAS ESPÉCIES DE EUCALIPTO NAS LINHAS E ENTRELINHAS, NO BAIRRO ÁGUA BONITA EM PIRACICABA-SP.

FIGURA 20. DIFERENÇA NO CRESCIMENTO DE GRAMÍNEAS ABAIXO DAS ESPÉCIES EM AMBAS AS FOTOS A ESPÉCIE E. CAMALDULENSIS (ESQUERDA) E E. TORELLIANA (DIREITA) NO BAIRRO ÁGUA BONITA EM PIRACICABA-SP.

FIGURA 21. ÍNDICE DE ÁREA FOLIAR $\left(\mathrm{M}^{2} \mathrm{M}^{-2}\right)$ NAS ESPÉCIES DE EUCALIPTO ANTES E DEPOIS DA DESRAMA, NO BAIRRO ÁGUA BONITA EM PIRACICABA-SP. 
FIGURA 22. TAXA DE INTERCEPTAÇÃO (\%) NAS ESPÉCIES DE EUCALIPTO ANTES E DEPOIS DA DESRAMA, NO BAIRRO ÁGUA BONITA EM PIRACICABA-SP.

FIGURA 23. RADIAÇÃO FOTOSSINTETICAMENTE ATIVA $\left(\mu M O L \mathrm{M}^{-2} \mathrm{~S}^{-1}\right)$ NAS ESPÉCIES DE EUCALIPTO NAS LINHAS E ENTRELINHAS, ANTES E DEPOIS DA DESRAMA, NO BAIRRO ÁGUA BONITA EM PIRACICABA-SP. . .48

FIGURA 24. ÍNDICE DE ÁREA FOLIAR $\left(M^{2} M^{-2}\right)$ NAS ESPÉCIES DE EUCALIPTO, NA EECF EM ANHEMBI-SP.

FIGURA 25. TAXA DE INTERCEPTAÇÃO (\%) NAS ESPÉCIES DE EUCALIPTO, NA EECF EM ANHEMBI-SP

FIGURA 26. RADIAÇÃO FOTOSSINTETICAMENTE ATIVA $\left(\mu M O L \mathrm{M}^{-2} \mathrm{~S}^{-1}\right)$ NAS ESPÉCIES DE EUCALIPTO, NA EECF EM ANHEMBI-SP.

FIGURA 27. DIFERENÇA NO CRESCIMENTO INICIAL DAS ESPÉCIES E. UROPHYLLA $X E$. GRANDIS (ESQUERDA) E E. CLOEZIANA (DIREITA) NA EECF EM ANHEMBI-SP.............................53 


\section{LISTA DE TABELAS}

TABELA 1. ANÁLISE DOS VALORES MÉDIOS DO ÍNDICE DE ÁREA FOLIAR (IAF), TAXA DE INTERCEPTAÇÃO (TI) E RADIAÇÃO FOTOSSINTETICAMENTE ATIVA (RFA) NAS LINHAS E ENTRELINHAS DOS PLANTIOS DE EUCALIPTO E. UROPHYLLA X E. GRANDIS COM 2 ANOS DE IDADE, ESPAÇAMENTO 3 X 2 M DUPLO ÚNICO NO BAIRRO FLORESTA EM PIRACICABA-SP.

TABELA 2. RESUMO DOS RESULTADOS DOS VALORES MÉDIOS DO ÍNDICE DE ÁREA FOLIAR (IAF); DA TAXA DE INTERCEPTAÇÃO (TI) E DA RADIAÇÃO FOTOSSINTETICAMENTE ATIVA (RFA) NAS LINHAS E ENTRELINHAS DE PLANTIOS DE 9 ESPÉCIES DE EUCALIPTO COM 60 MESES DE IDADE, ESPAÇAMENTO 3 X 2 M NO BAIRRO ÁGUA BONITA EM PIRACICABA-SP. 45

TABELA 3. RESUMO DOS RESULTADOS DO COMPARATIVO DE ANTES DE DEPOIS DA DESRAMA DOS VALORES MÉDIOS DO ÍNDICE DE ÁREA FOLIAR (IAF); DA TAXA DE INTERCEPTAÇÃO (TI) E DA RADIAÇÃO FOTOSSINTETICAMENTE ATIVA (RFA) NA LINHA E ENTRELINHAS DE PLANTIOS DE 7 ESPÉCIES DE EUCALIPTO COM 12 MESES DE IDADE, ESPAÇAMENTO 3 X 2 M NO BAIRRO ÁGUA BONITA EM PIRACICABA-SP.

TABELA 4. COMPARAÇ̃̃O DE INTENSIDADE DE DESBASTE 55\%, 70\% E 85\% SOBRE OS VALORES MÉDIOS DO ÍNDICE DE ÁREA FOLIAR (IAF); DA TAXA DE INTERCEPTAÇ̃̃O (TI) E DA RADIAÇÃO FOTOSSINTETICAMENTE ATIVA (RFA) NAS LINHAS E ENTRELINHAS DE PLANTIOS DE EUCALIPTO E. GRANDIS COM 228 MESES DE IDADE, ESPAÇAMENTO ORIGINAL 3 X 2 M NA EECF EM ITATINGA-SP. .50

TABELA 5. RESUMO DOS RESULTADOS DOS VALORES MÉDIOS DO ÍNDICE DE ÁREA FOLIAR (IAF); DA TAXA DE INTERCEPTAÇÃO (TI) E DA RADIAÇÃO FOTOSSINTETICAMENTE ATIVA (RFA) NAS LINHAS E ENTRELINHAS DE PLANTIOS DE 24 ESPÉCIES DE EUCALIPTO COM 12 MESES DE IDADE, ESPAÇAMENTO 3 X 2 M NA EECF EM ANHEMBI-SP. .54 


\section{LISTA DE ABREVIATURAS E SIGLAS}

$\begin{array}{ll}\text { RFA } & \text { Radiação fotossinteticamente ativa } \\ \text { IAF } & \text { Índice de área foliar } \\ \mathrm{TI} & \text { Taxa de Interceptação } \\ \mathrm{SAF} & \text { Sistema Agroflorestal } \\ \mathrm{m} & \text { metros } \\ \mathrm{nm} & \text { nanômetros } \\ \mu \mathrm{mol} \mathrm{m} \mathrm{s}^{-1} & \quad \text { micro mols por metro quadrado segundo } \\ \mathrm{E} . & \text { Eucalyptus } \\ \text { EECFI } & \text { Estação Experimental de Ciências Florestais de Itatinga } \\ \text { EECFA } & \text { Estação Experimental de Ciências Florestais de Anhembi } \\ \text { E. urograndis } & \text { E. urophylla } x \text { E. grandis }\end{array}$




\section{INTRODUÇÃO}

O gênero Eucaliptus, popularmente conhecido como "Eucalipto", designa o gênero de várias espécies vegetais originárias da Oceania, cujos centros de origem estão principalmente na Austrália e outras espécies em menor número na Nova Guiné, Indonésia, Filipinas e Timor (CIB, 2008).

As primeiras plantas de eucalipto foram trazidas ao Brasil no início do século XX (1904) pelo Engenheiro Agrônomo Edmundo Navarro de Andrade, que a serviço da Companhia Paulista de Estradas de Ferro foi até a Austrália com o objetivo de encontrar uma árvore com dupla aptidão: fornecer carvão para as locomotivas e madeira para os postes e dormentes das estradas de ferro na região Sudeste. Vendo o potencial do eucalipto, a Companhia Paulista iniciou em 1909 a construção do Horto Florestal de Rio Claro para expandir a produção de mudas e espécies do eucalipto. Inicialmente foram plantadas 144 espécies diferentes somando no total 38 milhões de árvores (MARTINI, 2004).

Economicamente o setor florestal brasileiro, até o ano de 1965, era pouco expressivo, tanto que as atividades de manejo das florestas plantadas e nativas eram insignificantes e realizadas, na sua grande maioria, em pequena escala e em condições de baixo emprego de tecnologia e gestão. A produção de carvão vegetal tinha como fonte de matéria-prima as florestas nativas. Nesta época, poucos empregos eram gerados e o país importava quase todo o produto florestal industrial. Além disso, não havia interesse por parte dos produtores rurais e empresários florestais em investir em projetos de reflorestamento devido, entre outras coisas, a baixa rentabilidade, ao longo prazo de maturação e aos riscos elevados. Com a política de incentivos fiscais ao reflorestamento, que vigorou de 1965 a 1988, ocorreu um crescimento significativo da área reflorestada no país. Os gêneros florestais que mais se destacaram foram Pinus e Eucalyptus devido ao rápido crescimento, à boa qualidade da madeira, à adaptabilidade ao clima e ao solo das regiões sul e sudeste. Com o fim dos incentivos fiscais, a taxa de aumento das áreas plantadas no Brasil praticamente foi nula, enquanto o aumento na demanda por madeira continuou crescente, passando a consumir madeiras de antigos povoamentos florestais a longas distâncias, rotulados anteriormente de inviáveis (VALVERDE et al., 2005).

Atualmente, frente à necessidade de conservação das matas nativas, devido a crescente pressão para conservação ambiental, e associada às características de crescimento 
e adaptação do eucalipto, a produção voltou a ganhar força. Assim, iniciou-se a motivação para destinar essa produção também para madeira serrada em diversas aplicações (JANKOWSKY et al., 2000). Esta necessidade de reduzir o uso da madeira de florestas naturais tem no plantio de eucalipto uma alternativa rentável e ambientalmente conservacionista, além de uma base técnico-científica graças às evoluções tecnológicas e de manejo.

Dados do IBGE (2014) apontam que a área plantada com eucaliptos no Brasil atingiu 6.951.145 de hectares. Sendo que os estados com maior produção em ordem decrescente são: Minas Gerais, Mato Grosso do Sul, São Paulo, Paraná, Rio Grande do Sul, Bahia, Santa Catarina e Espírito Santo.

O principal motivo que direciona na escolha das espécies de eucalipto a ser plantada é a demanda do mercado por determinado produto. As espécies a serem escolhidas devem apresentar as melhores características para determinadas funções, que aliadas às caracteríticas edafoclimáticas da região, resultarão no melhor retorno econômico. Segundo Angeli et al. (2005), as espécies indicadas em função do uso são:

Celulose: E. alba, E. dunnii, E. globulus, E. grandis, E. saligna, E. urophylla e E. grandis $x$ E. urophylla (híbrido).

Lenha e carvão: E. brassiana, E. camaldulensis, E. citriodora, E. cloeziana, E. crebra, E. deglupta, E. exserta, E. globulus, E. grandis, E. maculata, E. paniculata, E. pellita, E. pilularis, E. saligna, E. tereticornis, E. tesselaris e E. urophylla.

Serraria: E. camaldulensis, E. citriodora, E. cloeziana, E. dunnii, E. globulus, E. grandis, E. maculata, E. maidenii, E. microcorys, E. paniculata, E. pilularis, E. propinqua, E. punctata, E. resinifera, E. robusta, E. saligna, E. tereticornis e E. urophylla.

Móveis: E. camaldulensis, E. citriodora, E. deglupta, E. dunnii, E. exserta, E. grandis, E. maculata, E. microcorys, E. paniculata, E. pilularis, E. resinifera, E. saligna e E. tereticornis. 
Laminação: E. botryoides, E. dunnii, E. grandis, E. maculata, E. microcorys, E. pilularis, E. robusta, E. saligna e E. tereticornis.

Caixotaria: E. dunnii, E. grandis, E. pilularis e E. resinifera.

Construções: E. alba, E. botryoides, E. camaldulensis, E. citriodora, E. cloeziana, E. deglupta, E. maculata, E. microcorys, E. paniculata, E. pilularis, E. resinifera, E. robusta, E. tereticornis e E. tesselaris.

Dormentes: E. botryoides, E. camaldulensis, E. citriodora, E. cloeziana, E. crebra, E. deglupta, E. exserta, E. maculata, E. maidenii, E. microcorys, E. paniculata, E. pilularis, E. propinqua, E. punctata, E. robusta e E. tereticornis.

Postes: E. camaldulensis, E. citriodora, E. cloeziana, E. maculata, E. maidenii, E. microcorys, E. paniculata, E. pilularis, E. punctata, E. propinqua, E. tereticornis e E. resinifera.

Estacas e moirões: E. citriodora, E. maculata e E. paniculata.

Óleos essenciais: E. camaldulensis, E. citriodora, E. exserta, E. globulus, E. smithii e E. tereticornis.

Dependendo da função econômica do plantio desejada, o cultivo de eucalipto torna-se rentável a médio ou a longo prazo, e durante o desenvolvimento da floresta há a necessidade por parte do produtor de obter renda a curto prazo para mantê-la e também arcar com os diversos custos da propriedade. Em alguns casos o produtor se vê limitado pela ocupação do solo pelo plantio do eucalipto e assim, uma alternativa para o ganho com a floresta em curto prazo pode ser feito por meio do desbaste ao longo dos anos até a colheita do eucalipto, porém, em pequenas áreas o ganho com o desbaste é pouco significativo, levando o produtor buscar outras alternativas de obtenção de recurso.

Muitos estudos têm sido realizados no intuito de explorar alternativas de ocupação do solo abaixo do eucalipto em sistemas agroflorestais, a fim de aproveitar a radiação que atravessa a floresta e as condições de microclima criadas pelas árvores. Em boa 
parte dos estudos realizados com consórcio de eucalipto com espécies agrícolas, o espaçamento e a idade da floresta são as principais variáveis que infuenciam os resultados de produtividade das culturas associadas as árvores. As variáveis idade e espaçamento são importantes pois elas determinam se haverá radiação suficiente para o desenvolvimento das plantas agrícolas associadas. No entanto, estudos com o objetivo de estudar a quantidade de radiação disponível para o desenvolvimento de culturas consorciadas, tendo como influência das variáveis de índice de área foliar e taxa de absorção de radiação das árvores são escassos. Além disso, o efeito das práticas de manejo de desrama e desbaste sobre a radiação restante abaixo das árvores também carece de maiores estudos.

Os objetivos deste trabalho foram determinar qual a influência das espécies, e das práticas de manejo de desrama e desbaste do eucalipto sobre quantidade de radiação fotossintéticamente ativa disponível para o desenvolvimento de vegetação sob a floresta e calcular o índice de área foliar e a taxa de inteceptação de radiação das árvores utilizando a radiação fotossiteticamente ativa.

Tendo como hipótese base que as espécies de eucalipto, as práticas de desrama e desbaste têm influência sobre o índice de área foliar e na taxa de absorção das árvores, consequentemente alterando as quantidades de radiação fotossinteticamente ativa disponível para as plantas sob a floresta. 


\section{REVISÃO BIBLIOGRÁFICA}

\subsection{Radiação Solar}

A irradiação solar, mais comumente chamada de radiação solar, quando considerada como uma onda, possui um comprimento e uma frequência. Ela também pode ser considerada como fluxo de partículas, chamado de fótons, ou quanta (TAIZ et al., 2015). A radiação solar é de todos os fatores ambientais o mais importante, responsável por regular a fotossíntese e, consequentemente, a sobrevivência das plantas, seu crescimento e adaptação (ABOUZIENA E ABD EL WAHED, 2013).

Abouziena e Abd El Wahed (2013) citaram que em todo o habitat a intensidade da luz varia temporalmente (sazonalmente e diariamente) e espacialmente (ZERVOUDAKIS et al., 2012). Assim, os vegetais desenvolveram aclimatação e plasticidade para lidar com os regimes de luz variadas (ZHANG et al., 2003). A maioria das espécies de plantas têm a capacidade de desenvolver alterações anatômicas, morfológicas, fisiológicas e bioquímicas em resposta às diferentes intensidades de luz (PAIVA et al., 2003; ZHANG et al., 2003; ZERVOUDAKIS et al., 2012). Chapman e Carter (1976) estabeleceram o limite mínimo para se ter uma resposta fototrópica, na maioria das plantas o mesmo encontra-se entre 100 e 200 foot candle ( 1 foot candle é de cerca de 10,764 Lux). Porém, intensidades de luz tão baixas quanto 10 lux (0,93 foot candle), que ocorre no crepúsculo, podem gerar uma resposta fototrópica (VERGARA, 1978).

De todo espectro da radiação solar, uma faixa merece destaque; a da Radiação Fotossinteticamente Ativa (RFA). Essa faixa tem como característica ser visível e é responsável pela ativação da fotossíntese nas plantas. Citada por Taiz el al. (2015) como podendo ser medida por sensores que captam ondas de 400 a $700 \mathrm{~nm}$, essa radiação pode ser expressa em função de energia $\left(\mathrm{W} \mathrm{m}^{-2}\right)$ ou quanta $\left(\mathrm{mol} \mathrm{m} \mathrm{m}^{-2} \mathrm{~s}^{-1}\right.$ (MCCREE, 1981) ou ainda, em $\mu \mathrm{mol} \mathrm{m} \mathrm{m}^{-2} \mathrm{~s}^{-1}$. É importante notar que o RFA é uma medida do tipo de irradiância. $\mathrm{Na}$ pesquisa sobre a fotossíntese, quando RFA é expressa em uma base quântica, muitas vezes é dado o termo espacial "densidade fluxo de fótons fotossintéticos". No entanto Holmes et al. (1985) sugeriu que o termo "densidade" seja retirado, porque no Sistema Internacional de Unidades pode significar a área ou volume. 
A RFA sofre variações estacional e também pelo estado do tempo no local de coleta. Isso pode ser verificado quando é feita a relação da RFA com a Radiação Global: a variação sazonal e da cobertura do céu na relação entre a radiação fotossinteticamente ativa e global é da ordem de aproximadamente $50 \%$, sendo menor no inverno (39,13\%), período caracterizado, no local, por dias de céu aberto e maior no verão $(44,07 \%)$ para dias nublados. (FRISINA et al., 1998).

A radiação solar é usada pelas plantas na fotossíntese para converter dióxido de carbono da atmosfera em componentes de carbono orgânico para seu crescimento, respiração e reprodução. O limite superior de conversão de energia em cultivos florestais é provavelmente em torno de $6 \%$ da radiação fotossinteticamente ativa (RFA) baseado em resultados de experimentos agrícolas (Jarvis e Leverenz, 1983). Linder (1985) calculou que se toda radiação incidente (RFA) fosse interceptada e convertida em biomassa com uma conversão eficiente em $6 \%$, o potencial de produção de biomassa (matéria seca acima do solo) na Austrália seria de 80 ton ha ${ }^{-1} \mathrm{a}^{-1}$, em Hobart (2,6 GJ m $\mathrm{m}^{-2}$ ) a 100 ton ha $\mathrm{a}^{-1}$ no norte da Austrália (3.7 GJ $\mathrm{m}^{-2} \mathrm{a}^{-1}$ ). Os máximos valores reportados de produtividade estão bem abaixo do potencial de produção estimado (CROMER, 1995).

A RFA é uma importante variável para as áreas da biologia, ecologia e agricultura, mas em dados meteorológicos de rotina a mesma não é observada, ou se existe essa observação, é levada em pouca consideração em relação a outras variáveis. O cálculo anterior de quantidade de RFA muitas vezes usado na metodologia em climatologia experimental mostra que a proporção de radiação fotossinteticamente ativa em relação à radiação global apresenta valores de $60 \%$. A tendência de variação diária da RFA em um dia ensolarado apresenta um padrão de pico único mais alto ao meio-dia e baixo no começo da manhã e no final da tarde. Já em dias nublados, a variação diária RFA flutua enquanto existe mudanças de cobertura das nuvens, e a RFA em dias nublados é maior do que em dias de céu limpo. Também existe uma variação anual, uma tendência que é menor no inverno e na primavera, porém maior no verão e outono. As causas dessa variação nas medições está relacionada com a elevação solar, cobertura de nuvens, vapor de água e poeira em suspensão na atmosfera. Em alguns casos essas variações são muito complexas, sendo necessários mais estudos (LIU et al., 2007). 
Sob a radiação solar direta, a RFA é de cerca de $2000 \mu \mathrm{mol} \mathrm{m} \mathrm{m}^{-2} \mathrm{~s}^{-1}$, embora os valores mais altos podem ser medidos em altitudes elevadas, sendo que esse valor correspondente em unidades de energia é de cerca de $400 \mathrm{~W} \mathrm{~m}^{-2}$. (TAIZ et al., 2015).

De acordo com Baumgartner (1956) grande parte da radiação que ultrapassa o dossel está dentro da faixa do infravermelho, emitida pelos corpos, já a irradiância dentro da faixa do visível é mais restritiva que a infravermelha. Czarnowski e Slomka (1959) descobriram que no chão de uma floresta de pinheiros com 25 anos, a luz direta e a luz difusa pelo dossel não supera $50 \%$ da luz original. Grande parte da luz que entra abaixo do dossel é difusa, já a direta é dispersa pela cultura e pela atmosfera (REIFSNYDER \& LULL, 1965). A difusa é o resultado da suavização e reflexão da luz direta. Ela permite que algumas espécies de plantas se desenvolvam abaixo das árvores de uma floresta pois existem plantas adaptadas a essa situação como o caso da espécie Euterpe edulis (Jussara) que necessita da cobertura de árvores para seu desenvolvimento inicial.

Existem algumas espécies que são exigentes em radiação direta, porém a conversão da radiação fotossinteticamente ativa das culturas é baixa, não atingindo 1\% para a maioria das mesmas. Em condições ótimas registram-se eficiências de 3 a 4\% para plantas do tipo C3 e de 5\% a 6\% para plantas do tipo C4 (BERNARDES, 1987).

A produtividade de matéria seca em plantas madeireiras, assim como em culturas agrícolas temperadas, foi encontrada como sendo linearmente relacionada com a acumulação da energia radiante interceptada pela folhagem (Jarvis e Leverenz, 1983).

A produtividade real de uma cultura é determinada pela interação entre ambiente e fatores genéticos. Em comum com outras culturas, a produtividade de eucalipto plantado é diretamente relacionado com a quantidade de radiação solar interceptada pela folhagem do dossel. Muitos estudos têm demonstrado a forte relação entre produção de matéria seca e energia radiante interceptada pela folhagem, sendo evidente que qualquer incremento na produtividade de uma cultura florestal primeiramente necessita de um incremento no índice de área foliar, a fim de interceptar uma maior proporção de energia disponível. Porém, existem outras razões para o IAF ser menor do que o ótimo em casos particulares, pois, existe um número de outras limitações, sendo as principais: estresse nutricional, estresse hídrico, efeito da temperatura e propriedades físicas do solo. Essas limitações ambientais de crescimento do eucalipto podem ser melhoradas por tratamentos 
silviculturais aplicados antes e depois do plantio, acrescentando assim a interceptação da radiação e crescimento (CROMER, 1995).

Em estudos agrícolas e florestais, a RFA pode ser utilizada para o cálculo de indireto de uma importante variável, o Índice de Área Foliar (IAF) razão entre a área foliar do dossel e a unidade de superfície projetada no solo $\left(\mathrm{m}^{2} \mathrm{~m}^{-2}\right)$, através de um método indireto pela adaptação da lei de Lambert-Beer, onde pode-se estimar a transmissão da radiação em uma cultura, para isso requer o conhecimento da densidade do fluxo de radiação acima da mesma e abaixo da mesma e o fator conhecido como coeficiente de extinção da luz (LINDER, 1985).

Estudos relacionados com morfologia, anatomia e ecofisiologia vegetal, permite a obtenção de um indicador fundamental para a compreensão das respostas da planta a fatores ambientais específicos (LOPES et al., 2004; MORAES et al., 2013). Os métodos indiretos são os mais fáceis e a maneira mais rápida de estimação do IAF que vem sendo amplamente aplicado (NACKAERTS et al.,2000; WELLES \& COHEN, 1996; SANCHES et al., 2008).

Borges (2009) cita que a radiação fotossinteticamente ativa absorvida pelo dossel é determinada considerando o índice de área foliar (IAF) e a RFA, mediante a utilização da lei de Beer. Além disso, a lei de Beer tem sido utilizada em vários modelos ecofisiológicos (Century, Cenw, Fullcam, G'day, Gendec, Grazplan, Linkages, e Promod) desenvolvidos na Austrália (WANG, 2001). Um simples modelo (lei de Lambert-Beer) é usado para estimar a transmissão da luz em uma cultura, que requer o conhecimento da densidade do fluxo de radiação acima da mesma, o índice de área foliar (IAF) da cultura e o fator conhecido como coeficiente de extinção da luz (LINDER, 1985). Segundo Borges (2009) a lei de Beer descreve simplificadamente o decréscimo exponencial da luz ao percorrer verticalmente toda extensão da cobertura vegetal. Em uma cobertura foliar razoavelmente homogênea, a atenuação da radiação pode ser calculada por meio da equação de extinção de luz (lei de Lambert-Beer) (LARCHER, 2004): 


$$
I z=I 0 \cdot e^{-K} \cdot \operatorname{IAF}
$$

Em que:

$\mathbf{I} \mathbf{z}$ = intensidade da radiação a uma determinada altura dentro da cobertura vegetal, RFA abaixo do dossel $\left(\mu \mathrm{mol} \mathrm{m}^{-2} \mathrm{~s}^{-1}\right)$;

lo = intensidade da radiação no topo da cobertura vegetal, RFA acima do dossel $\left(\mu \mathrm{mol} \mathrm{m} \mathrm{m}^{-2}\right)$;

$\mathbf{K}=$ coeficiente de extinção, representa o grau de diminuição da radiação no interior da cobertura vegetal, seja por absorção ou espalhamento;

$$
\text { IAF = Índice de área foliar }\left(\mathrm{m}^{2} \mathrm{~m}^{-2}\right) .
$$

No entanto, o essa equação apresenta limitações, referentes ao coeficiente de extinção da luz (K), Queiroz (2013) citou que é frequente haver para a mesma espécie diferentes estimativas de valores de $\mathrm{K}$, devido as diferenças na estrutura do copado, protocolos de amostragem, ângulos solar zenital e azimutal, ou, inclusivamente, nos métodos utilizados para o desenvolvimento dos modelos. Portanto, os valores de K são específicos para determinadas condições de avaliação e dificilmente a aplicação do modelo de Beer-Lambert com um valor de $\mathrm{K}$ calculado sob determinadas circunstâncias produzirá estimativas rigorosas do IAF numa situação em que as condições não sejam mantidas idênticas para árvores espaçadas. Assim, o valor de $\mathrm{K}$ poderá ser mais complicado do que a simples atribuição de um valor fixo, como é feito na forma mais geral da aplicação da Lei de Beer-Lambert. O autor conclui que é questionável que o K seja um só em função da espécie, como é geralmente considerado, ignorando as características do povoamento.

O total de energia no ambiente absorvida pelos dosséis das árvores é uma variável determinante da transpiração e fotossíntese, com aplicação em agricultura e estudos ambientais. Em espécies de árvores, é importante determinar as relações da energia radiante com as plantas, que dependem da geometria da copa das árvores e folhas, 
densidade de área, espaçamento entre árvores e outros fatores que determinam as perdas e os ganhos de energia, as medições, bem como as estimativas complexas devido ao número de fatores envolvidos (Angelocci et al., 2004). Eloy et al. (2012) cita que a energia de radiação solar absorvida pelo dossel vegetativo é uma variável de grande importância, pois diversos processos fisiológicos das plantas relacionam-se diretamente com a quantidade de RFA, radiação global incidente e temperatura do ar, influenciando na eficiência do desenvolvimento das plantas (CARON, 2003). Além disso, a energia de radiação solar absorvida pelas plantas é fator determinante da taxa fotossintética e pode limitar a produção e o acúmulo de biomassa (PILAU, 2005).

Caron et al. (2012) citou que o conhecimento da interceptação da radiação luminosa pela copa das árvores sob espaçamentos variados permite ao silvicultor avaliar a necessidade e o planejamento adequados de intervenções, tais como roçadas, capinas ou uso de produtos químicos, possibilitando o melhor aproveitamento desses recursos. Nos espaçamentos menores, devido à rápida formação do dossel, a necessidade de tratos culturais é menor quando comparadas aos espaçamentos maiores. Esse fato também está relacionado com a disponibilidade de radiação luminosa, já que a quantidade dessa variável meteorológica para as plantas daninhas é diminuída à medida que ocorre o fechamento do dossel pela cultura.

Em alguns casos, parte da energia que passa pelas copas, é o suficiente para o desenvolvimento de plantas abaixo das árvores. Williams (1994) estabeleceu limites para o crescimento e desenvolvimento de plantas, ele afirmou que as plantas que crescem com irradiância maior que $200 \mathrm{\mu mol} \mathrm{m}^{-2} \mathrm{~s}^{-1}$ exibem um crescimento e desenvolvimento RAZOÁVEL. Plantas que crescem entre 100 e $199 \mu \mathrm{mol} \mathrm{m} \mathrm{m}^{-2} \mathrm{~s}^{-1}$ exibem um crescimento e desenvolvimento adequado, enquanto as plantas cultivadas com menos do que $100 \mu \mathrm{mol} \mathrm{m}$ ${ }^{2} \mathrm{~s}^{-1}$ exibem crescimento abaixo do adequado ou inadequado. 


\subsection{Sistemas agroflorestais com Eucalipto}

Em um estudo com consórcio de eucalipto E. grandis no espaçamento de $3 \times 2$ metros com milho de Passos et al. (1992) teve como resultados: a interação que mais se destacou foi obtido com a intercalação de três fileiras de milho no plantio do eucalipto; a produção de grãos foi afetada pelo aumento do número de fileiras de milho; e os sistemas agroflorestais mostraram-se mais eficientes no uso da área, proporcionando uma redução na área plantada de até $66 \%$ e uma redução de até $20 \%$ no custo de implantação do eucalipto; o uso do sistema agroflorestal pode ser uma alternativa para a redução dos custos florestais, tanto para a empresa como para o produtor rural em programas de fomento florestal.

Schreiner e Baggio (1989) estudaram o sistema agroflorestal entre a soja (Glycine max L.) e o eucalipto, no espaçamento de $3 \times 2$ metros, concluiu-se que houve uma tendência para o incremento da altura do eucalipto no sistema consorciado.

Em outro estudo realizado por Schreiner (1989), com sistema agroflorestal de soja com o eucalipto (E. grandis) no espaçamento de $3 \times 2$ metros. Concluiu que, até dezoito meses da implantação, a soja não prejudicou o eucalipto e favoreceu o seu crescimento. 0 volume de madeira, nos sistemas consorciados, foi em média de $49,3 \mathrm{~m}^{3}$ ha ${ }^{-1}$, já o plantio solteiro foi de $37,3 \mathrm{~m}^{3} \mathrm{ha}^{-1}$. A densidades de plantio não afetaram a soja mas, tenderam a uma maior produtividade de $1.734 \mathrm{~kg} / \mathrm{ha}$ na densidade populacional de 400.000 plantas/ha. Além de que a soja incrementou $30 \%$ sobre o custeio. A soja também impediu o desenvolvimento das plantas daninhas sem afetar negativamente o eucalipto. Os melhores resultados em produtividade foram com cinco linhas de soja, espaçadas de 0,5 m entrelinhas de eucalipto.

Schreiner e Balloni (1989), realizaram um estudo do feijão com eucalipto ( $E$. grandis) em espaçamento de $3 \times 2$ metros até 35 meses, e verificaram que a implantação da floresta não afetou a cultura agrícola, mas favoreceram seu crescimento. Ainda nesse período o volume de madeira dos sistemas agroflorestais, em média, foi de $150,8 \mathrm{~m}^{3} \mathrm{ha}^{-1}$, e $125,8 \mathrm{~m}^{3} \mathrm{ha}^{-1}$ no monocultivo do eucalipto. Não houve influencia na cultura do feijão, registrando uma tendência de aumento de produtividade quando a densidade chegou a 200 mil plantas ha ${ }^{-1}\left(917 \mathrm{~kg} \mathrm{ha}^{-1}\right)$. Houve um retorno de 30\% do capital investido. 
Stape e Martini (1992), estudaram o consorcio de arroz com o E. grandis e $E$. saligna, e obtiveram como resultados: que o arroz mostrou-se apto para consorciação com o eucalipto; a consorciação do eucalipto com arroz aumentou a produção volumétrica em $5 \%$, na idade de 52 meses, comparativamente ao plantio solteiro. A partir destes resultados a empresa do estudo passou a utilizar o sistema agrofloresta, constatando que: a produção florestal da consorciação, em escala comercial, foi superior ao plantio solteiro, tanto para o E. grandis como para o E. saligna, com a mesma tendência dos resultados experimentais, evidenciando-se os efeitos benéficos desta prática agroflorestal; a melhor produtividade apresentada pelo eucalipto resultou em uma melhor taxa interna de retorno e menor custo de produção para o plantio consorciado, para as duas espécies de eucalipto; os ganhos de produtividade também resultaram em menores custos de corte e a remoção da madeira em relação aos plantios solteiros.

Oliveira (2005) realizou vários experimentos envolvendo espécies de Eucalyptus e Brachiaria brizantha em diferentes arranjos estruturais de sistemas agrosilvipastoris. Em termos de matéria natural e matérias seca o melhor resultado obtido para a gramínea foi no espaçamento $3 \times 3+10$ metros. Em outro experimento para verificar quais foram as maiores alturas de eucalipto aos 18 meses em diversos espaçamentos no sistema silvipastoril, as alturas das plantas foram maiores nos espaçamentos mais adensados (3,33 × 2 m, 3,33 × 3 m e $5 \times 2$ m). Já aos 27 meses para medição da DAP (diâmetro na altura do peito) verificou-se maior DAP nos espaçamentos $10 \times 4 \mathrm{~m}$ seguido de $10 \times 3 \mathrm{~m}$, mostrando assim a influência do espaçamento no diâmetro da árvore, sendo que o espaçamento é um fator importante na hora do plantio em sistema silvipastoril para determinar o produto final.

Fontan (2007) estudou a dinâmica de copa de dois clones de eucalipto em sistema agroflorestal, com espaçamento $9,5 \times 4,0 \mathrm{~m}$ submetidos a três níveis de desrama zero, um terço e um quarto. A primeira desrama foi realizada aos nove meses de idade das plantas em todos os tratamento e a segunda aos 15 meses somente para os tratamentos com duas desramas, feito em $80 \%$ das árvores antes do plantio de culturas. Apresentou como resultados que o clone de E.camaldulensis $\times$ E. grandis (clone 58) teve melhores resultados em termos de transmissividade de RFA por possuir uma copa menos densa que o clone de E.urophylla $\times$ E. grandis (clone 19), permitindo que as plantas abaixo dos eucaliptos fossem mais beneficiadas. 


\section{MATERIAL E MÉTODOS}

\subsection{Radiômetro}

O aparelho utilizado para a coleta da RFA abaixo do dossel das árvores foi o radiômetro ELETM com um único sensor fotoelétrico específico para a banda da radiação fotossinteticamente ativa (banda visível $400 \mathrm{~nm}$ a $700 \mathrm{~nm}$ ). Ele possui um visor aonde apresenta as leituras instantaneamente em $\mu \mathrm{mol} \mathrm{m} \mathrm{m}^{-2} \mathrm{~s}^{-1}$, possui uma chave para lateral na qual se pode multiplicar e dividir o valor apresentado em 10. Não possui capacidade de armazenamento, portanto as leituras eram anotadas em caderno. Seu único sensor possui um angulo de visão de $180^{\circ}$, necessitando ser constantemente nivelado em relação ao solo. Calibrado para sensor SKP 210.

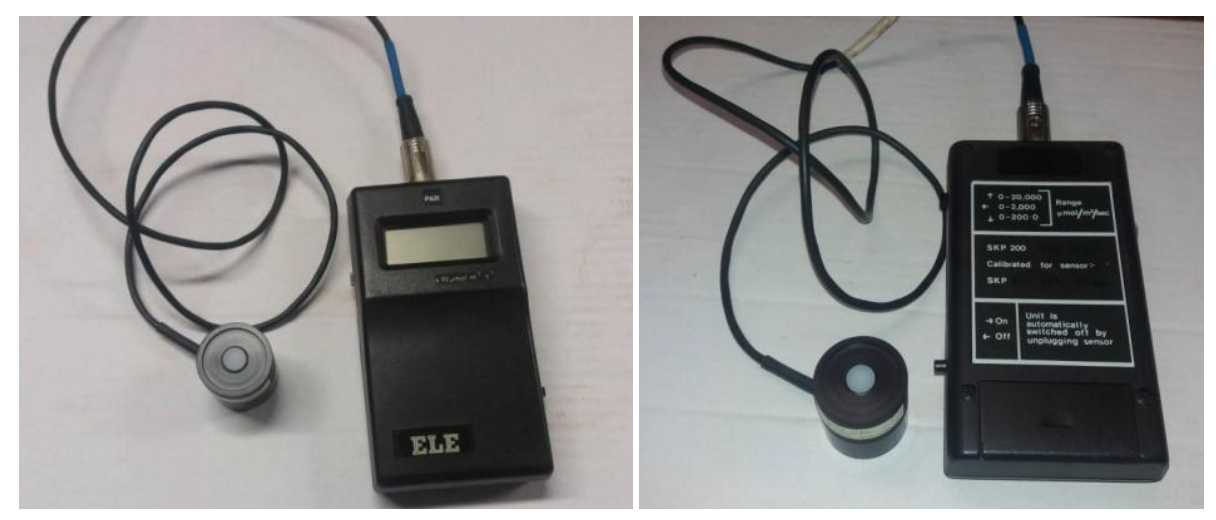

Figura 1. Radiômetro ELETM com sensor fotoelétrico específico de frente (esquerda) e de verso (direita).

\subsection{Método de Leitura}

As leituras da RFA utilizando-se o sensor foram padronizadas de forma que tenham características iguais, as leituras foram realizadas com o sensor a uma altura de 1,20 metros em relação ao solo, altura essa equivalente à altura dos radiômetros nos postos meteorológicos. Observando o experimento por cima, vemos que as leituras nas linhas (L) foram feitas na metade da distância entre uma árvore e outra e nas entrelinhas (EL), as leituras foram feitas no centro do quadrilátero formado por quatro árvores $(A)$, conforme ilustrado na Figura 2: 


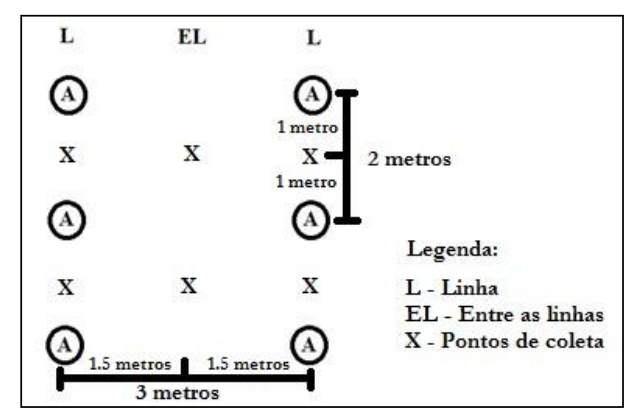

Figura 2. Exemplificação do método de leitura para os todos os experimentos com espaçamento $3 \times 2 \mathrm{~m}$.

Devido ao fato do aparelho disponível possuir apenas um sensor e não uma barra de sensores onde o resultado seria uma média entre os mesmos. Foram coletados neste trabalho vinte um a cinquenta pontos por dia de coleta, utilizando os valores médios em cada ponto coletado. Assim, foi feita uma média no campo em cada ponto coletado com um raio de $30 \mathrm{~cm}$, para evitarmos o erro de coletar no ponto valores extremos, pois o sensor pode ficar encoberto por uma folha e/ou galho, ou ainda pegar um feixe de luz que passou diretamente sem qualquer cobertura.

As coletas foram feitas durantes os anos de 2015 e 2016, foram feitas três a cinco repetições em cada experimento tentando englobar os períodos de primavera-verão e outono-inverno. Os horários das coletas ocorreram dentro do período das 10 às 16 horas, período esse de maior intensidade do sol para leituras mais consistentes, a fim de evitar horários pós amanhecer e perto do crepúsculo onde há ocorrência de uma maior quantidade de radiação difusa. Quanto às condições atmosféricas durante a coleta, foram selecionados dias com céu aberto, sem nuvens e com velocidade do vento baixa ou nula. 


\subsection{Cálculo do Índice de Área Foliar através da Radiação Fotossinteticamente Ativa}

Neste estudo foi utilizado um método indireto de estabelecer o IAF através da Lei de Lambert-Beer, adaptada:

$$
\mathrm{IAF}=\frac{\operatorname{Ln}(\mathrm{RFAb} / \mathrm{RFAa})}{-\mathrm{K}}
$$

Em que:

$$
\text { IAF = Índice de área foliar }\left(\mathrm{m}^{2} \mathrm{~m}^{-2}\right)
$$

$\mathbf{R F A a}=$ radiação fotossinteticamente ativa acima do plantio de eucalipto, nesse caso, leituras das estações $\left(\mu \mathrm{mol} \mathrm{m}^{-2} \mathrm{~s}^{-1}\right)$;

$\mathbf{R F A b}=$ radiação fotossinteticamente ativa dentro do cultivo do eucalipto, utilizando-se a média de leitura de linhas e entrelinhas ( $\left.\mu \mathrm{mol} \mathrm{m} \mathrm{s}^{-1}\right)$;

$$
\mathbf{K}=\text { coeficiente de extinção da luz, que representa o quanto da radiação é }
$$
dispersada ao passar pela cobertura vegetal. Neste caso 0,50 (GAZARINI et at., 1990; SANDS e LANDSBERG, 2002; BORGES, 2009).

Foram considerados neste estudo os valores padrões de IAF específicos para a eucalipto 2 a $4,5 \mathrm{~m}^{2} \mathrm{~m}^{-2}$ (FOELKEL, 2005). 


\subsection{Cálculo da Taxa de Interceptação da Radiação}

Para o cálculo de Taxa de Interceptação de Radiação, foi utilizada a equação de Eloy et al. (2012):

$$
\text { \% interceptação }=[100-(\text { RFAb x 100/RFAa })]
$$

Em que:

\% interceptação = Taxa de Interceptação;

RFAa $=$ radiação fotossinteticamente ativa acima do plantio de eucalipto, nesse caso leituras das estações $\left(\mu \mathrm{mol} \mathrm{m} \mathrm{m}^{-2} \mathrm{~s}^{-1}\right.$;

$\mathbf{R F A b}=$ radiação fotossinteticamente ativa dentro do cultivo do eucalipto, utilizando-se a média de leitura de linhas e entrelinhas $\left(\mu \mathrm{mol} \mathrm{m} \mathrm{s}^{-2}\right)$;

3.5. Critério de categorização para o desenvolvimento de plantas nas linhas e entrelinhas dos plantios de eucalipto

De forma a enquadrar em categorias a radiação fotossinteticamente ativa para o crescimento e desenvolvimento de uma forma geral para plantas situadas abaixo dos plantios de eucalipto, foi adaptado o critério utilizado por Williams (1994):

Em que:

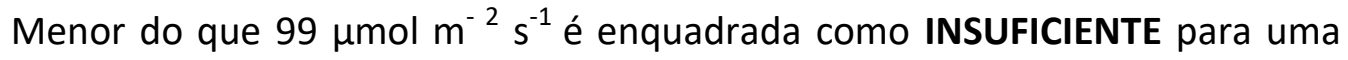
resposta fototrópica.

Entre 100 e $199 \mu \mathrm{mol} \mathrm{m}^{-2} \mathrm{~s}^{-1}$ é enquadrada como MíNIMA; 
Entre 200 e $799 \mu \mathrm{mol} \mathrm{m}{ }^{-2} \mathrm{~s}^{-1}$ é enquadrada como RAZOÁVEL;

Maior que $800 \mu \mathrm{mol} \mathrm{m} \mathrm{m}^{-2} \mathrm{~s}^{-1}$ é enquadrada como IDEAL para cultivos agrícolas exigentes em radiação, como por exemplo, o milho (EMBRAPA, 2010);

Para fins de conclusão deste trabalho foram considerados como aptos apenas os plantios de eucalipto que sob suas copas em suas entrelinhas e linhas atingiram os valores de RFA iguais ou superiores a $200 \mu \mathrm{mol} \mathrm{m} \mathrm{m}^{-2} \mathrm{~s}^{-1}$ categorizados como RAZOÁVEL e IDEAL.

\subsection{Calibração do aparelho e conversão de unidades}

A calibração do aparelho Radiômetro ELETM foi realizada pela comparação dos dados coletados a campo frente aos dados das estações meteorológicas da ESALQ mais próximas das áreas coletadas. Em média os valores coletados a campo pelo Radiômetro ELETM apresentaram valores inferiores quando comparados com os valores de referência das estações em: $32,37 \%$ nos experimentos realizados em Piracicaba; $34,33 \%$ no experimento realizado em Itatinga; e $22,15 \%$ no experimento de Anhembi, sendo assim todos os valores coletados foram corrigidos a partir desses valores.

O presente estudo coletou dados de três estações meteorológicas da ESALQ, localizadas nas cidades de Piracicaba, Anhembi e Itatinga, cidades estas no interior do estado de São Paulo.

Na estação meteorológica da ESALQ de Piracicaba, Anhembi e Itatinga, foram utilizados os dados de Radiação Solar Global (RG), considerando o valor de 0,47, proporção de RFA na RG (ASSIS E MENDEZ, 1989) e, posteriormente, fazendo a conversão de $\mathrm{W} \mathrm{m}^{-2} \mathrm{em}$ $\mu \mathrm{mol} \mathrm{m} \mathrm{m}^{-2} \mathrm{~s}^{-1}$ através do fator de conversão de 0,219. 


\subsection{Estações Experimentais e Postos Meteorológicos da ESALQ}

A Escola Superior de Agricultura 'Luiz de Queiroz' (ESALQ) campus da USP localizado em Piracicaba, conta com um Posto Meteorológico nas dependências do Departamento de Engenharia de Biossistemas. No Posto são coletadas várias informações meteorológicas, da qual se utilizaram dados da Radiação Fotossinteticamente Ativa ( $\mu \mathrm{mol} \mathrm{m}{ }^{-}$ $\left.{ }^{2} \mathrm{~s}^{-1}\right)$, coletados pela estação automática a cada 15 minutos. As coordenadas do posto são: Latitude: $22^{\circ} 42^{\prime} 30^{\prime \prime}$ S e Longitude: $47^{\circ} 38^{\prime} 00^{\prime \prime} \mathrm{O}$ e Altitude de 546 metros.

A Estação Experimental de Ciências Florestais de Anhembi (EECFA) é parte integrante da ESALQ e localiza-se na cidade de Anhembi-SP e está localizada a $90 \mathrm{~km}$ de distância do campus da ESALQ em Piracicaba. A estação conta com um Posto Meteorológico e para este estudo foram utilizados os dados de Radiação Solar $\left(\mathrm{W} \mathrm{m}^{-2}\right)$, coletados pela estação automática a cada 30 minutos. As coordenadas da Estação são: Latitude: $22^{\circ} 40^{\prime} \mathrm{S}$ e Longitude: $48^{\circ} 10^{\prime} \mathrm{O}$ e Altitude 455 metros.

A Estação Experimental de Ciências Florestais de Itatinga (EECFI) também é parte integrante da ESALQ e localiza-se na cidade de Itatinga-SP e está localizada a $180 \mathrm{~km}$ de distância do campus da ESALQ em Piracicaba. A estação conta com um Posto Meteorológico e para este estudo foram utilizados dados de Radiação Solar $\left(\mathrm{W} \mathrm{m}^{-2}\right)$, coletados pela estação automática a cada 30 minutos.

As coordenadas da Estação são: $23^{\circ} 10^{\prime}$ S e Longitude: $48^{\circ} 40^{\prime} \mathrm{O}$ e Altitude 850 metros.

\subsection{Experimento de avaliação de fileira dupla isolada Bairro Floresta, Piracicaba-SP}

Este experimento foi realizado em uma propriedade rural particular, localizada no bairro Floresta em Piracicaba, esta área possui alguns plantios de $E$. urophylla $X$ E. grandis. Para este experimento foi selecionada uma área com eucaliptos de 24 meses de idade plantados em fila dupla isolada com espaçamento $3 \times 2 \mathrm{~m}$. As linhas de plantio estão no sentido norte -sul e o terreno é levemente inclinado para leste com aproximadamente 80 árvores e tamanho $120 \times 2 \mathrm{~m}$. 

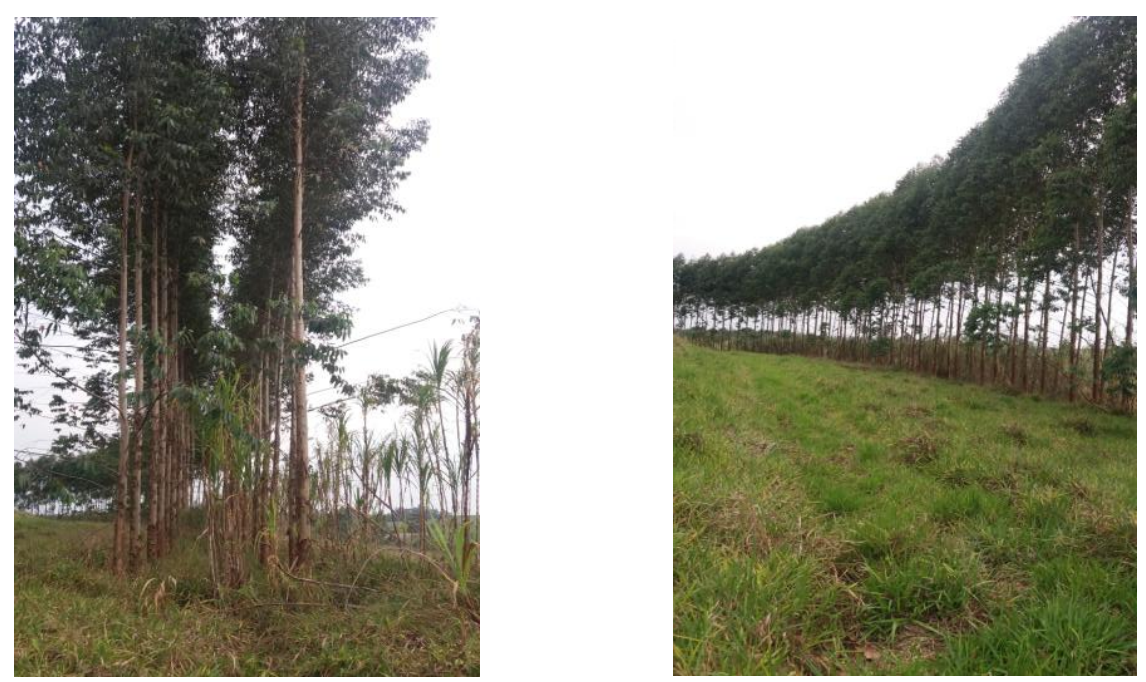

Figura 3. E. urophylla X E.grandis fileira dupla isolada com espaçamento $3 \times 2 \mathrm{~m}$, cobertura do solo (esquerda) e vista de fora (direita) no Bairro Floresta em Piracicaba-SP.

No experimento de 24 meses, o objetivo foi calcular o índice de área foliar, comparar as taxas de interceptação nas entrelinhas e linhas e classificar quanto à possibilidade de crescimento e desenvolvimento de plantas situadas abaixo do plantio de $E$. urophylla X E. grandis.

\subsection{Experimento de comparação entre espécies no Bairro Água Bonita, Piracicaba-SP}

Este experimento foi realizado em uma propriedade rural particular, localizada no bairro Água Bonita em Piracicaba, utilizada pelo Grupo Florestal Monte Olimpo (GFMO) da ESALQ para a realização de experimentos com espécies de eucaliptos.

Dentre eles foi selecionada para este experimento uma área com eucaliptos de 60 meses de idade, espaçamento $3 \times 2 \mathrm{~m}$, com nove espécies: E. camaldulensis, $E$. robusta, E. torelliana, E. urophylla, IPEF 137, E. saligna, E. propinqua, E. grandis e E. urophylla XE. grandis. As linhas de plantio estão no sentido sudoeste - nordeste e o terreno é plano, cada tratamento contendo aproximadamente 100 plantas e tamanho de $30 \times 20 \mathrm{~m}$. Neste experimento o objetivo foi comparar entre as espécies, os índices de área foliar, as taxas de interceptação nas entrelinhas e linhas, e classificar quanto à possibilidade de crescimento e desenvolvimento de plantas situadas abaixo dos plantios. 

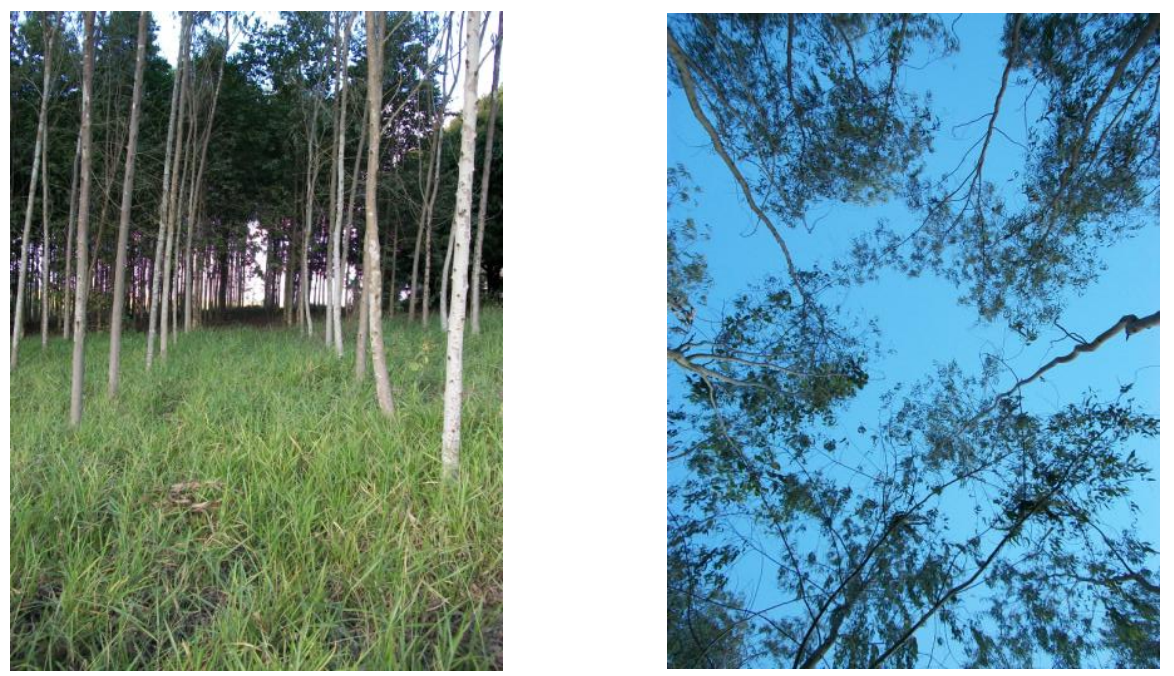

Figura 4. E. camaldulensis cobertura do solo (esquerda) e vista do dossel (direita) no Bairro Água Bonita em Piracicaba-SP.
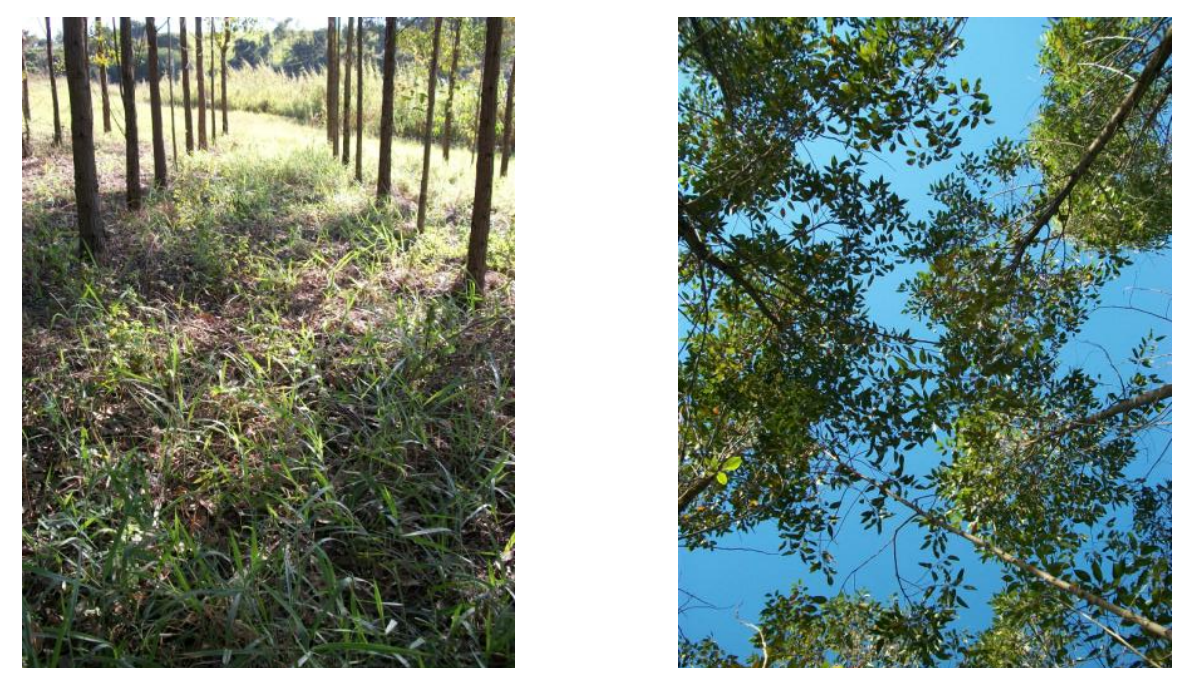

Figura 5. E. robusta cobertura do solo (esquerda) e vista do dossel (direita) no Bairro Água Bonita em Piracicaba-SP.
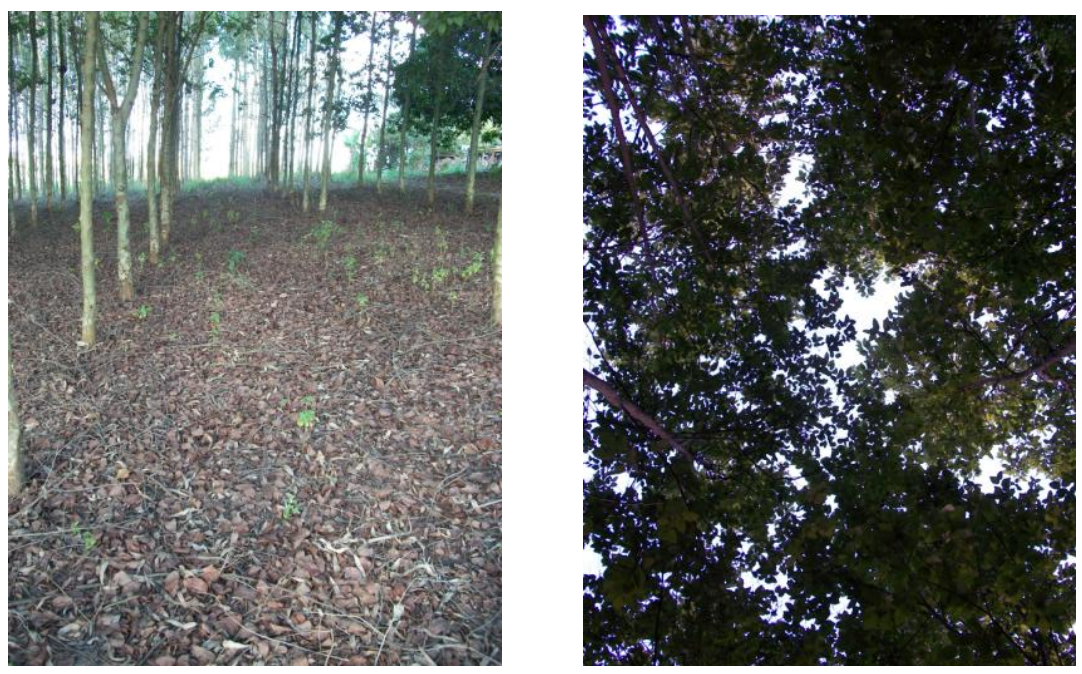

Figura 6. E. torelliana cobertura do solo (esquerda) e vista do dossel (direita) no Bairro Água Bonita em Piracicaba-SP. 

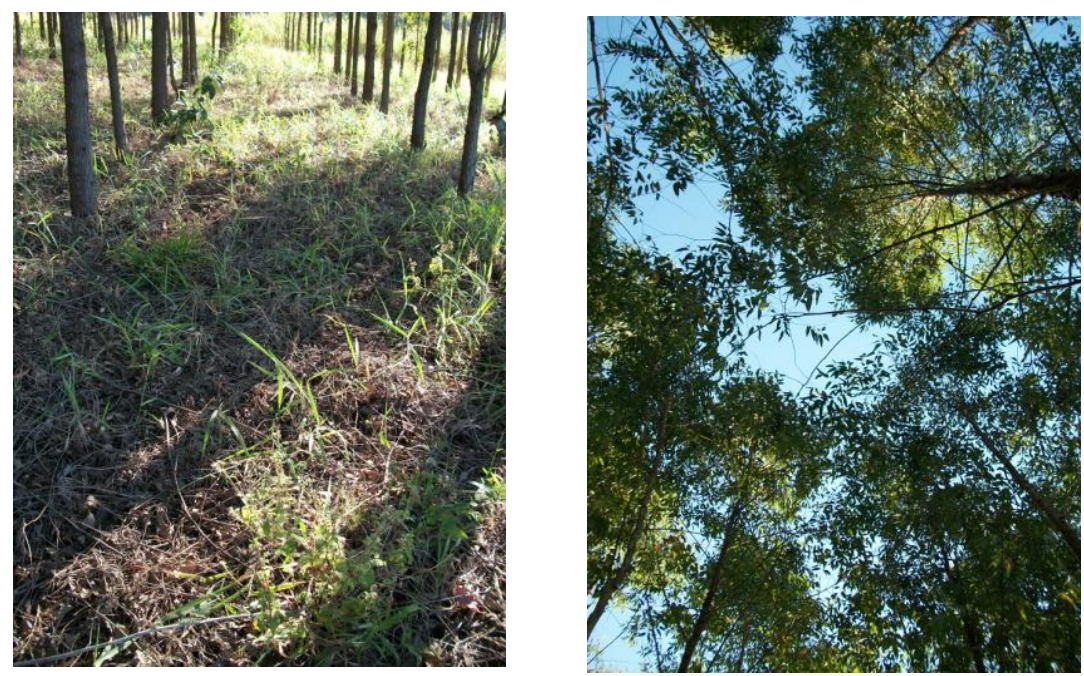

Figura 7. E. urophylla cobertura do solo (esquerda) e vista do dossel (direita) no Bairro Água Bonita em Piracicaba-SP.
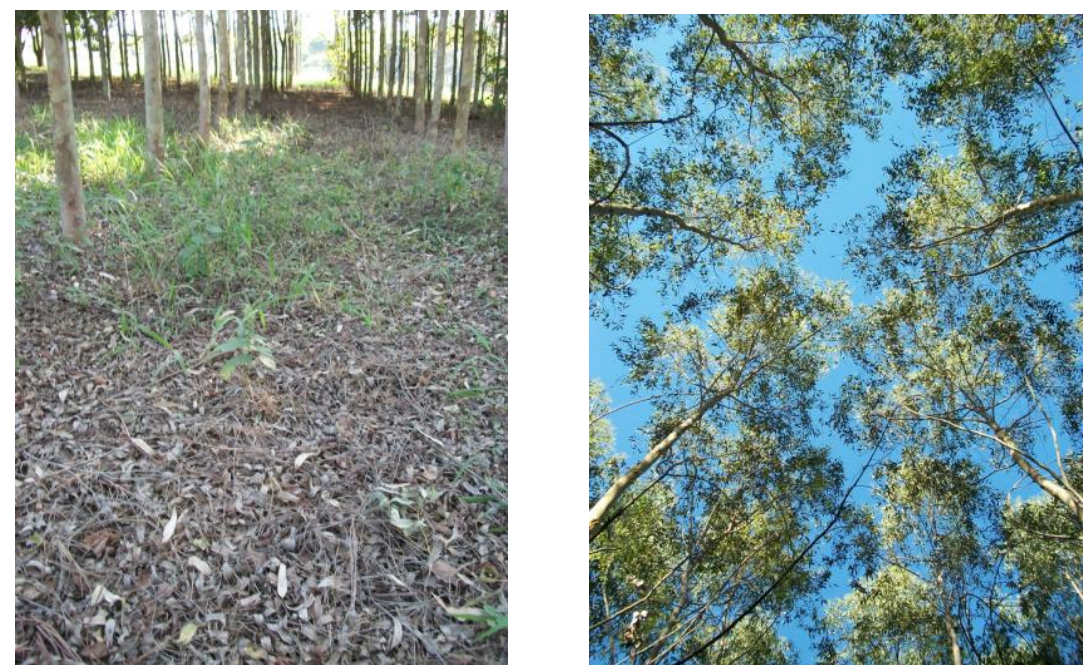

Figura 8. Espécies IPEF 137 cobertura do solo (esquerda) e vista do dossel (direita) no Bairro Água Bonita em Piracicaba-SP.
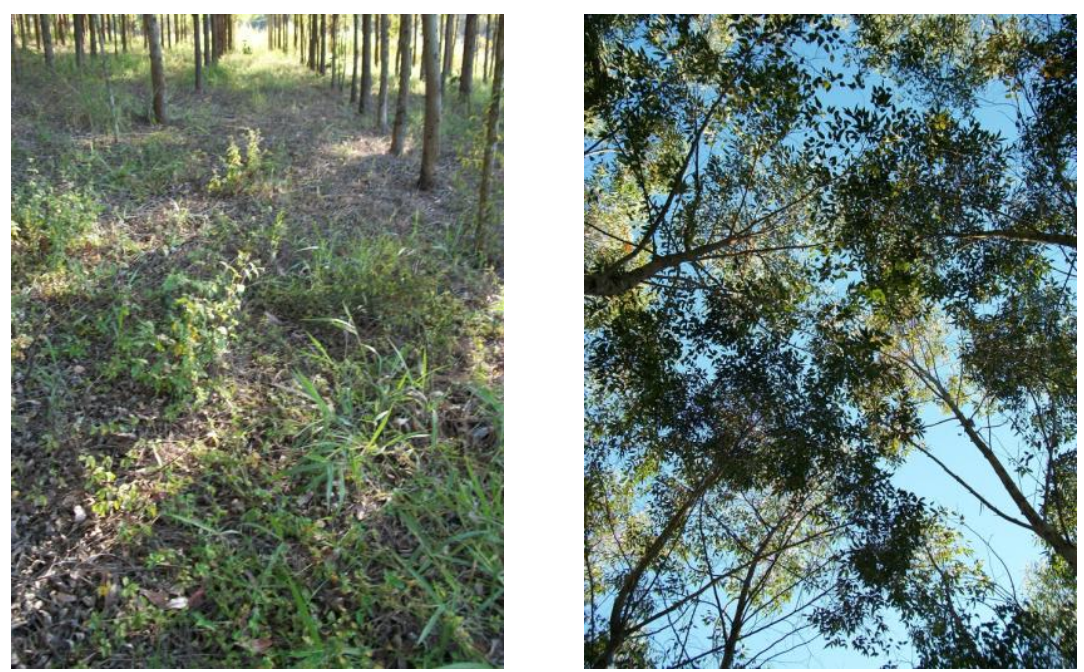

Figura 9. E. saligna cobertura do solo (esquerda) e vista do dossel (direita) no Bairro Água Bonita em Piracicaba-SP. 

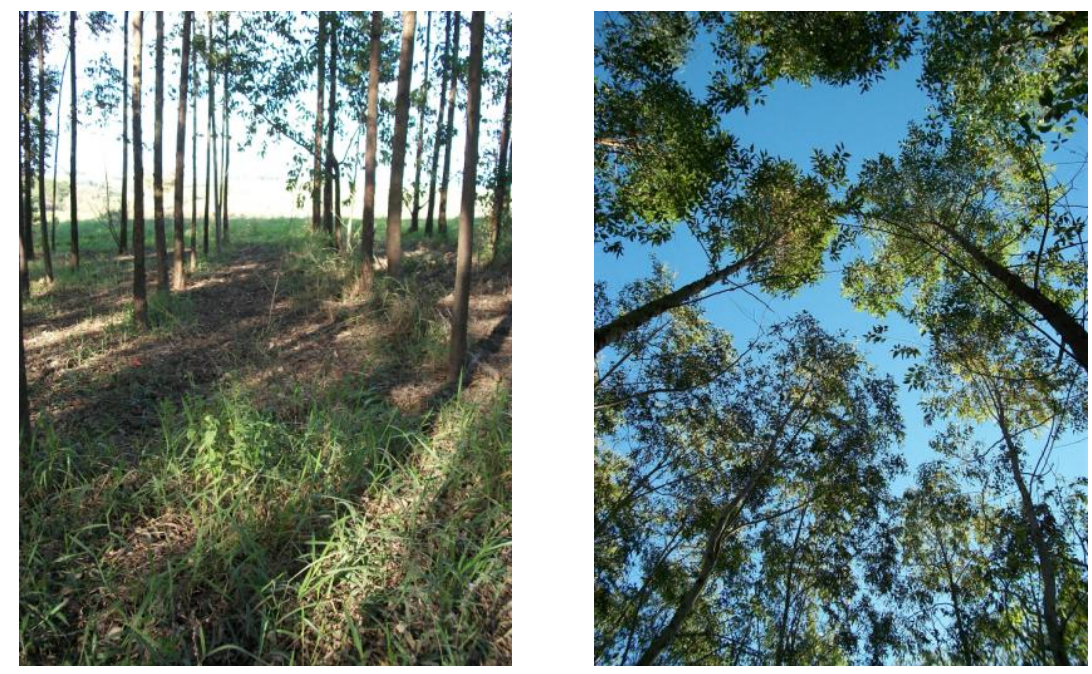

Figura 10. E. propinqua cobertura do solo (esquerda) e vista do dossel (direita) no Bairro Água Bonita em Piracicaba-SP.
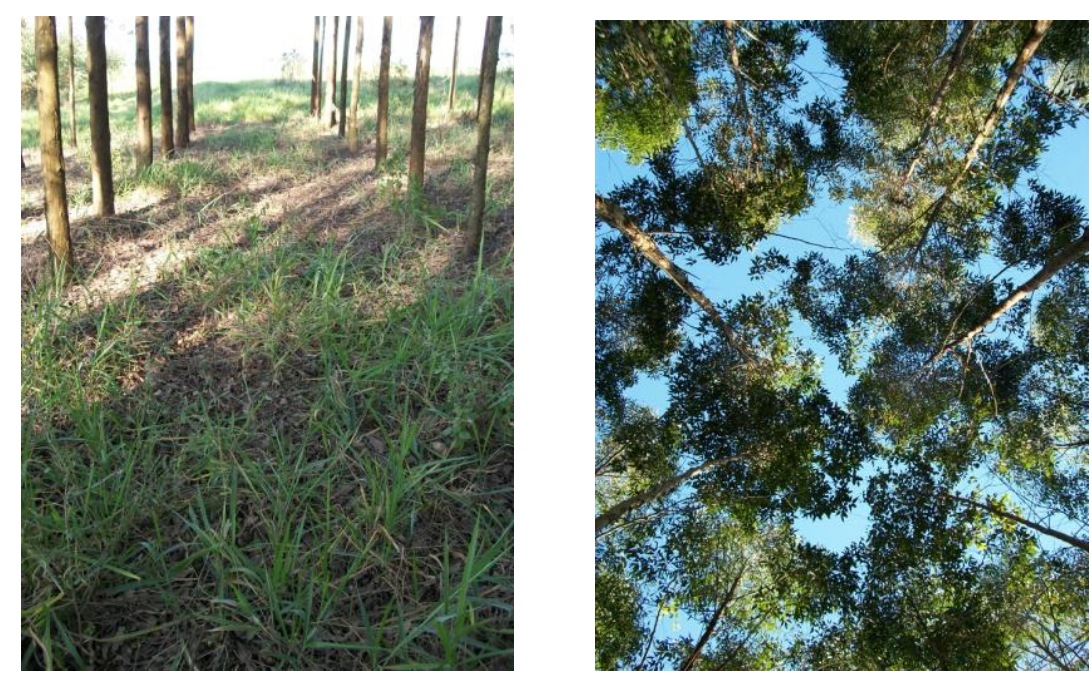

Figura 11. E. grandis cobertura do solo (esquerda) e vista do dossel (direita) no Bairro Água Bonita em Piracicaba-SP.
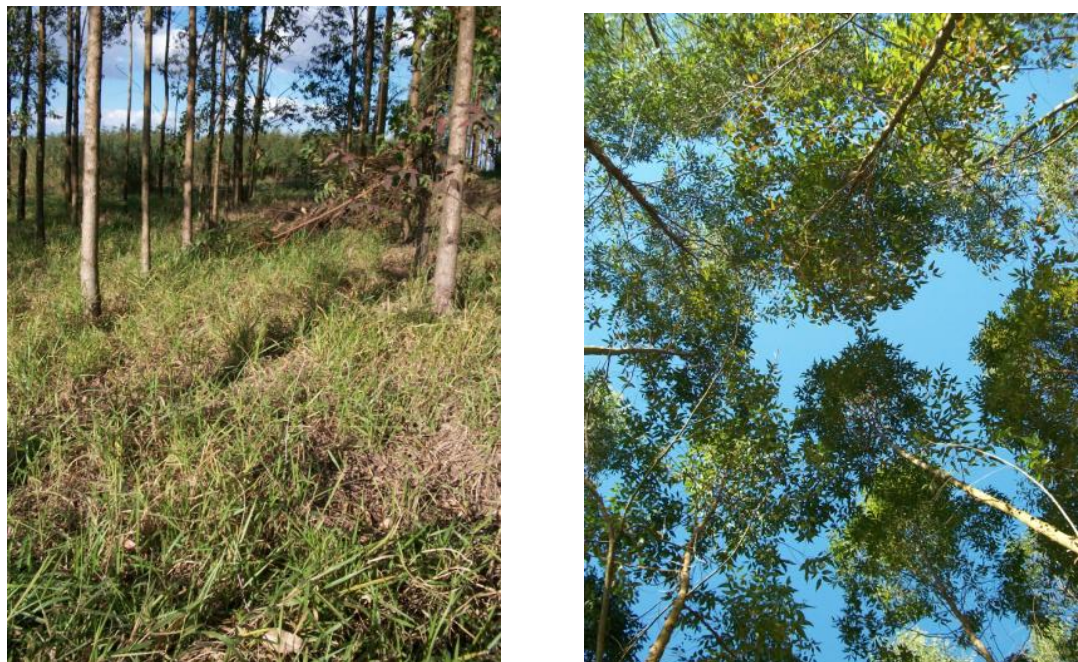

Figura 12. E. urophylla X E.grandis cobertura do solo (esquerda) e vista do dossel (direita) no Bairro Água Bonita em PiracicabaSP. 


\subsection{Experimento de avaliação de desrama no Bairro Água Bonita, Piracicaba-SP}

Este experimento foi realizado em uma propriedade rural particular, localizada no bairro Água Bonita em Piracicaba, utilizada pelo Grupo Florestal Monte Olimpo (GFMO) da ESALQ para a realização de alguns experimentos com espécies de eucaliptos.

Dentre eles foi selecionada para este experimento uma área com eucaliptos de 12 meses de idade, espaçamento $3 \times 2$ m, com sete espécies: E. urophylla, H13, E. grandis, H15, I144, E. citriodora, VT01. As linhas de plantio estão no sentido sudoeste nordeste e o terreno é plano, cada tratamento contendo aproximadamente 100 plantas e tamanho de $30 \times 20 \mathrm{~m}$. A desrama foi realizada em 1/3 da copa e a medição foi realizada uma semana depois da desrama. Neste experimento o objetivo foi comparar as mudanças ocorridas após a desrama nas espécies, em relação aos índices de área foliar, as taxas de interceptação nas entrelinhas e linhas, e classificar quanto à possibilidade de crescimento e desenvolvimento de plantas situadas abaixo dos plantios.

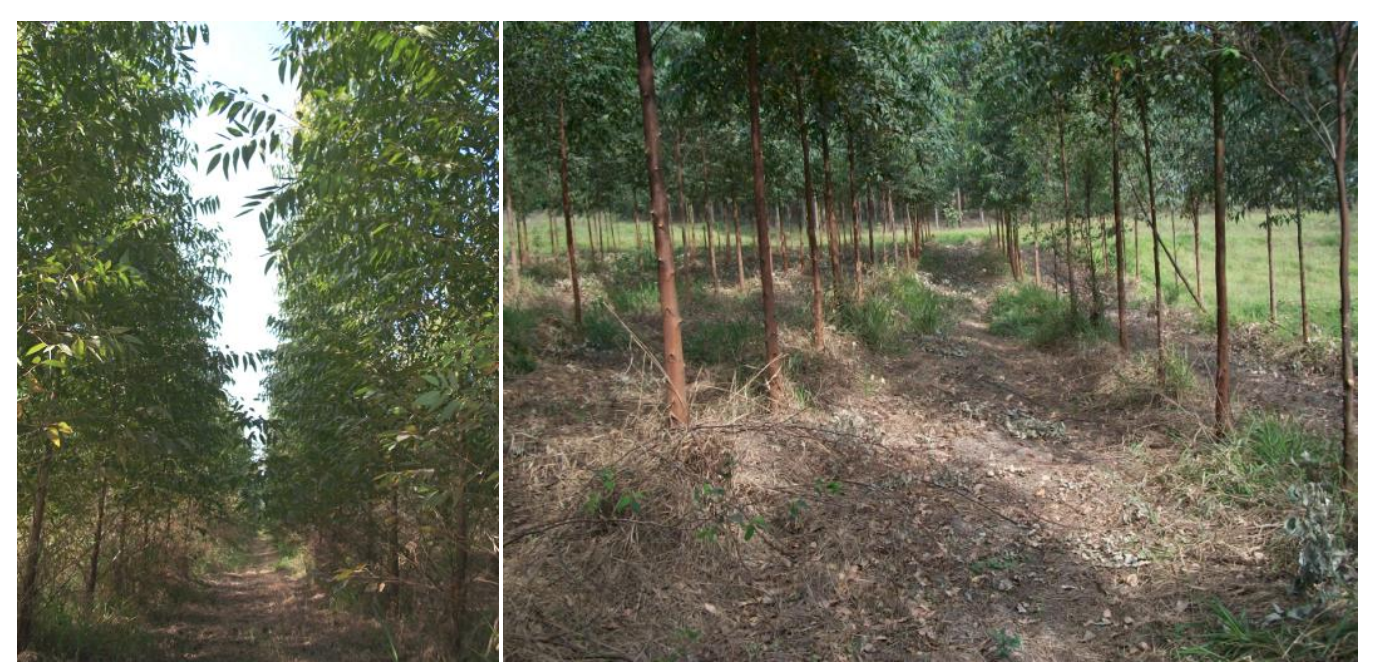

Figura 13. Espécies antes da desrama (esquerda) e depois da desrama (direita) no Bairro Água Bonita em Piracicaba-SP. 


\subsection{Experimento de comparação entre intensidades de desbaste na EECFI, Itatinga-SP}

Na área experimental de Itatinga foram coletadas informações de uma área de com E. grandis com 228 meses de idade e espaçamento original de $3 \times 2 \mathrm{~m}$ antes do desbaste, cada tratamento com tamanho aproximado $60 \times 60 \mathrm{~m}$, as linhas de plantio estão no sentido leste - oeste e o terreno é plano. O talhão sofreu ao longo do tempo desbastes seletivos para retirada de madeira e atualmente o experimento está com três graus de desbaste: $55 \%$, $70 \%$ e $85 \%$.

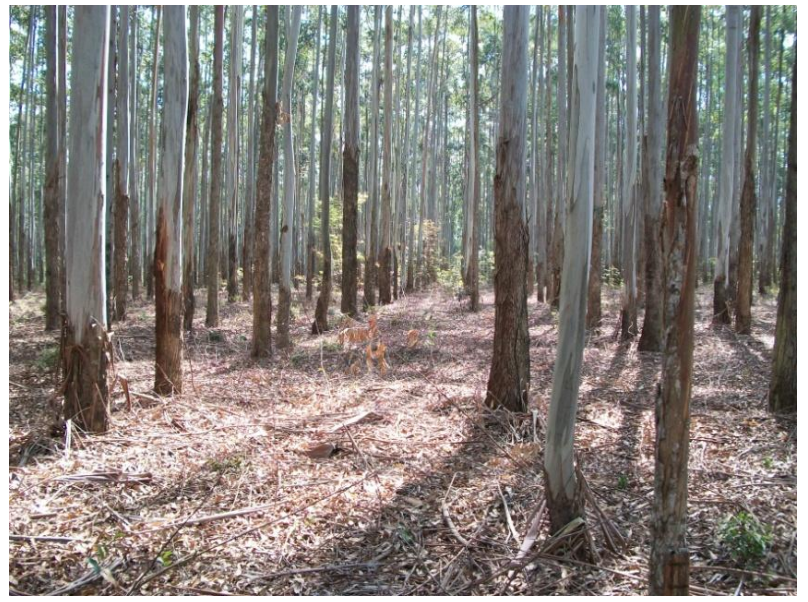

Figura 14. E. grandis com grau de desbaste de 55\% na Estação Experimental de Ciências Florestais em Itatinga-SP.

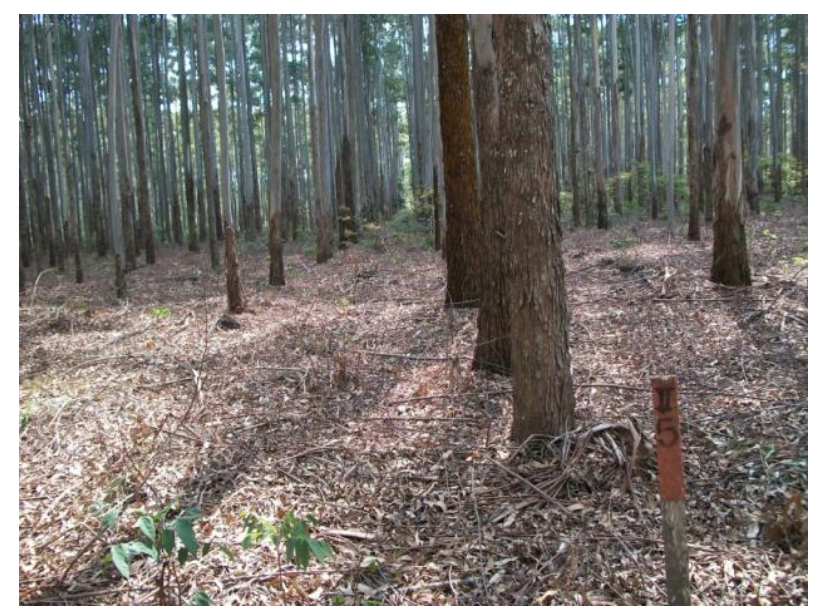

Figura 15. E. grandis com grau de desbaste de 70\% na Estação Experimental de Ciências Florestais em Itatinga-SP. 


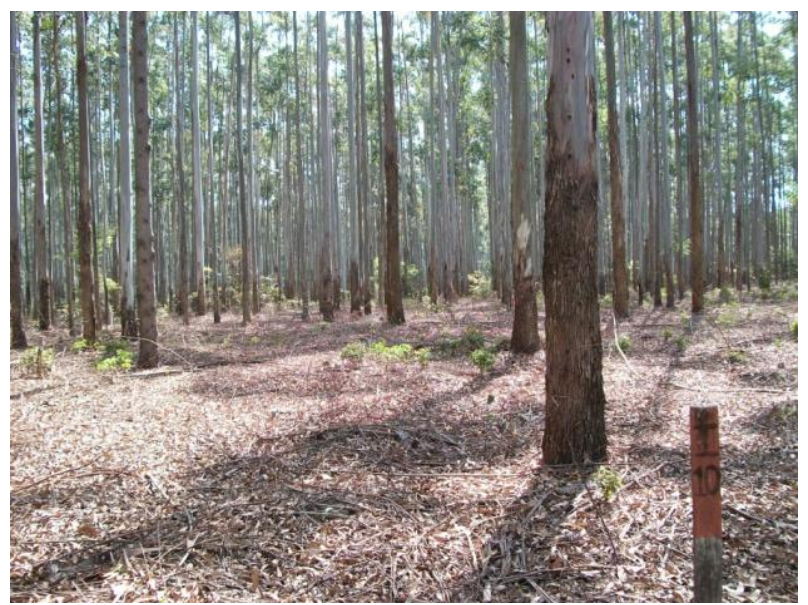

Figura 16. E. grandis com grau de desbaste de $85 \%$ na Estação Experimental de Ciências Florestais em Itatinga-SP.

Neste experimento o objetivo foi comparar entre os três graus de desbaste, o índice de área foliar, às taxas de interceptação nas entrelinhas e linhas e classificar quanto à possibilidade de crescimento e desenvolvimento de plantas situadas abaixo dos plantios.

\subsection{Experimento de comparação entre espécies na EECFA, Anhembi-SP}

Na experimental de Anhembi foram coletadas informações de um arboreto com 24 espécies de eucalipto, a área de cada espécie estava isolada das outras, sendo todas com idade de 12 meses e espaçamento $3 \times 2 \mathrm{~m}$, as linhas de plantio estão no sentido sudoeste - nordeste e o terreno é plano, cada tratamento contendo aproximadamente 144 plantas e tamanho de 36 × 24 m. São elas: E. maculata, E. cloeziana, E. citriodora, E. pilularis, E. toreliana, E. phaeothrica, E. microcorys, E. deglupta, E. paniculata, E. tereticornis, E. brassiana, E. camaldulensis, E. exserta, E. saligna, E. botryoides, E. grandis, E. urophylla, E. urophylla X E.grandis, E. pellita, E. propinqua, E. resinifera, E. dunni, E.torelliodora e $E$. robusta.

Neste experimento o objetivo foi comparar entre as espécies, os índices de área foliar, as taxas de interceptação nas entrelinhas e linhas, e classificar quanto à possibilidade de crescimento e desenvolvimento de plantas situadas abaixo dos plantios. 


\subsection{Análise Estatística}

A análise estatística foi realizada com o auxílio do programa computacional $R$. Em todos os experimentos foi realizada a análise de variância ANOVA e posteriormente o Teste Tukey a 5\% para identificar a diferença entre as médias. 


\section{RESULTADOS E DISCUSSÕES}

\subsection{Experimento de avaliação de fileira dupla isolada no Bairro Floresta, Piracicaba-SP:}

Na Tabela 1 se observa que a RFA nas entrelinhas, se enquadra na categoria RAZOÁVEL (entre 200 e $799 \mu \mathrm{mol} \mathrm{m}^{-2} \mathrm{~s}^{-1}$ ) e nas linhas se enquadra na categoria IDEAL (acima de $800 \mu \mathrm{mol} \mathrm{m} \mathrm{m}^{-2} \mathrm{~s}^{-1}$.

Tabela 1. Análise dos valores médios do Índice de Área Foliar (IAF), Taxa de Interceptação (TI) e Radiação Fotossinteticamente Ativa (RFA) nas linhas e entrelinhas dos plantios de eucalipto E. urophylla $\times$ E. grandis com 2 anos de idade, espaçamento 3 x 2 m duplo único no Bairro Floresta em Piracicaba-SP.

\begin{tabular}{cccc}
\hline Tratamento & IAF $\left(\mathbf{m}^{2} \mathbf{m}^{-2}\right) *$ & TI $(\%)$ & RFA na linha $\left(\boldsymbol{\mu} \mathbf{m o l ~ m}^{-2} \mathbf{s}^{-1}\right)$ \\
\hline Entrelinhas & 1,76 & $66,61 \mathrm{a}$ & $552,59 \mathrm{~b}$ \\
Linhas & & $46,3 \mathrm{~b}$ & $888,63 \mathrm{a}$ \\
\hline
\end{tabular}

Médias seguidas de letras iguais na mesma coluna não diferem pelo teste Tukey $(5 \%)$

*Valores de referência de IAF 2 a 4,5 $\mathrm{m}^{2} \mathrm{~m}^{-2}$ (Foelkel, 2005).

O arranjo de plantio em fileiras duplas permite uma maior entrada de radiação nas linhas que nas entre as linhas, devido às linhas ficarem expostas em um dos lados, enquanto nas entrelinhas existe uma maior cobertura dada à união das copas das árvores.

\subsection{Experimento de comparação entre espécies no Bairro Água Bonita, Piracicaba-SP:}

Na Figura 17 observa-se que a espécie E. torelliana apresentou valor de IAF maior do que o esperado para o eucalipto. As espécies E. robusta e E. camaldulensis apresentaram valores menores, valores de referência 2 a 4,5 $\mathrm{m}^{2} \mathrm{~m}^{-2}$ (Foelkel, 2005). 


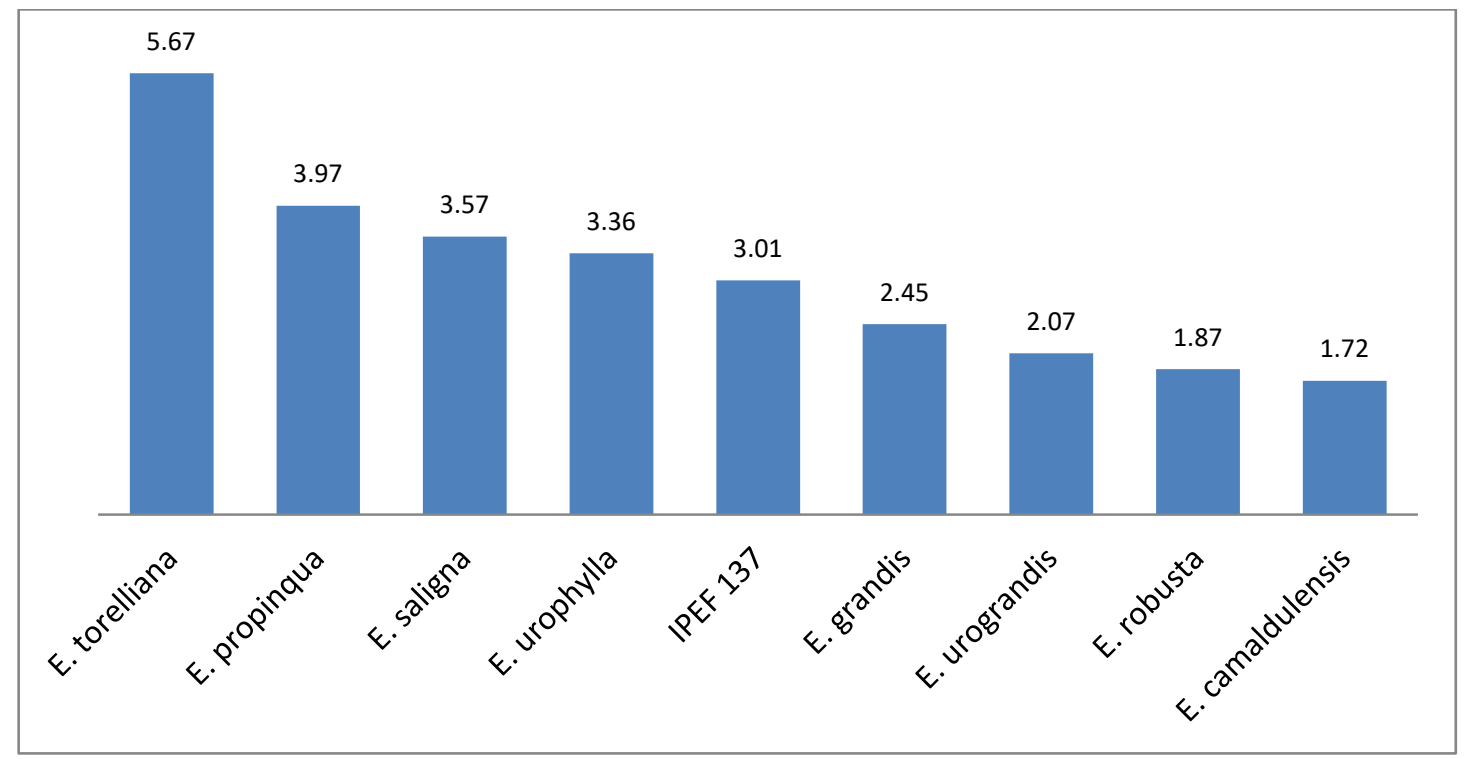

Figura 17. Índice de Área Foliar $\left(\mathrm{m}^{2} \mathrm{~m}^{-2}\right)$ nas espécies de eucalipto, no Bairro Água Bonita em Piracicaba-SP.

Os valores TI apresentados na Figura 18 mostra a diferença entre as espécies, e que a TI nas linhas é maior que nas entrelinhas.

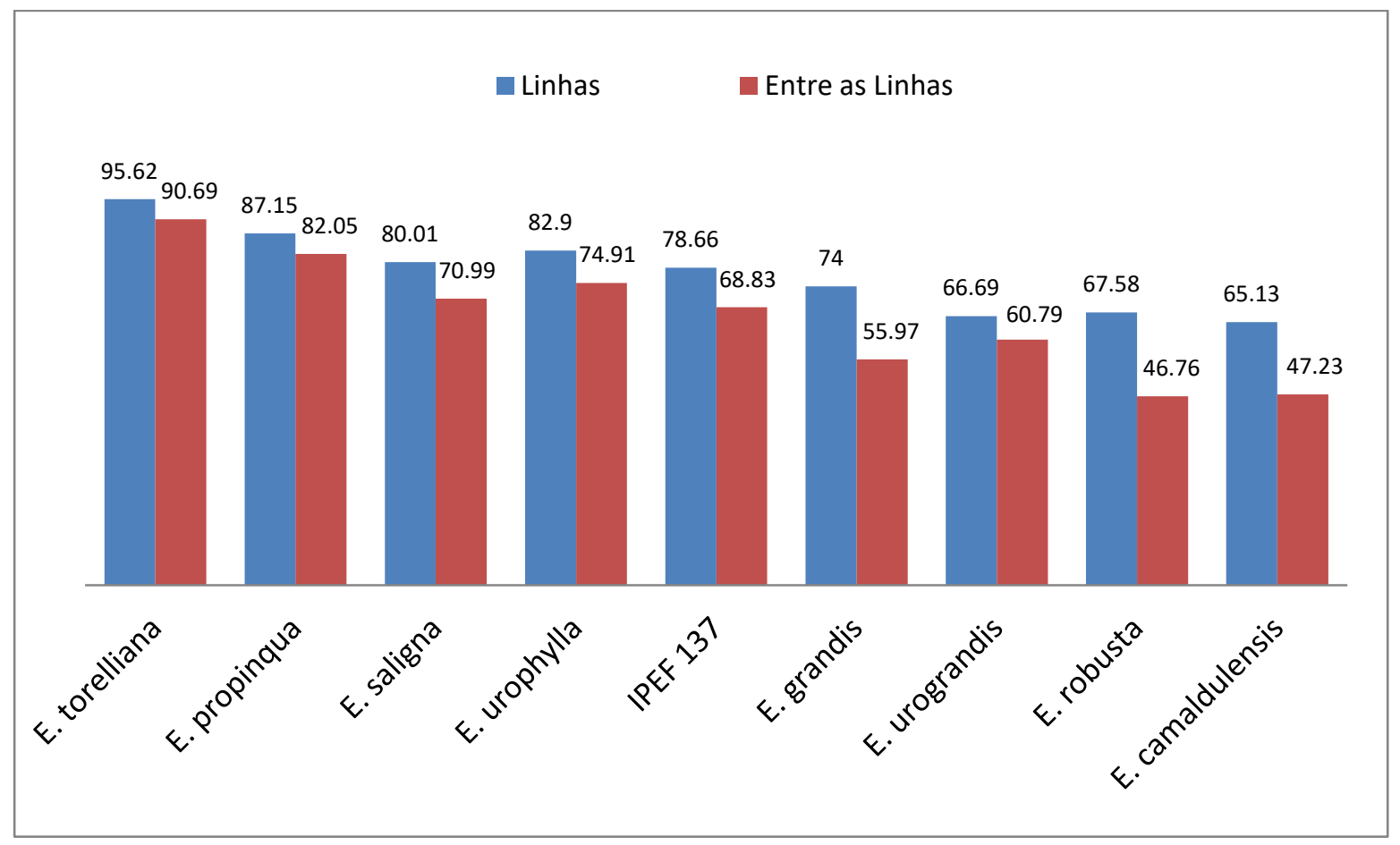

Figura 18. Taxa de Interceptação (\%) nas espécies de eucalipto nas linhas e entrelinhas, no Bairro Água Bonita em Piracicaba-SP. 
Nos valores de RFA observados na Figura 19 , nas linhas, as espécies $E$. camaldulensis, E. robusta, E. grandis, E. urophylla $\times$ E. grandis e E. saligna se enquadraram na categoria RAZOÁVEL (entre 200 e $799 \mu \mathrm{mol} \mathrm{m}^{-2} \mathrm{~s}^{-1}$ ); as espécies E. propinqua, E. urophylla e IPEF 137 na categoria MíNIMA (entre $100 \mu \mathrm{mol} \mathrm{m}^{-2} \mathrm{~s}^{-1}$ e $199 \mu \mathrm{mol} \mathrm{m}^{-2} \mathrm{~s}^{-1}$ ); e a espécie $E$. torelliana na categoria INSUFICIENTE (menor que $99 \mu \mathrm{mol} \mathrm{m}^{-2} \mathrm{~s}^{-1}$ ). Nas entrelinhas a RFA das espécies E. camaldulensis, E. robusta, E. grandis, IPEF 137, E. urophylla x E. grandis, E. urophylla e E. saligna se enquadraram na categoria RAZOÁVEL (entre 200 e $799 \mu \mathrm{mol} \mathrm{m}^{-2} \mathrm{~s}^{-}$ ${ }^{1}$ ); a espécie E. propinqua na categoria MíNIMA (entre $100 \mu \mathrm{mol} \mathrm{m}^{-2} \mathrm{~s}^{-1}$ e $199 \mu \mathrm{mol} \mathrm{m}^{-2} \mathrm{~s}^{-1}$ ); e a espécie E. torelliana na categoria INSUFICIENTE (menor que $99 \mu \mathrm{mol} \mathrm{m} \mathrm{m}^{-2} \mathrm{~s}^{-1}$ ), (Williams, 1994).

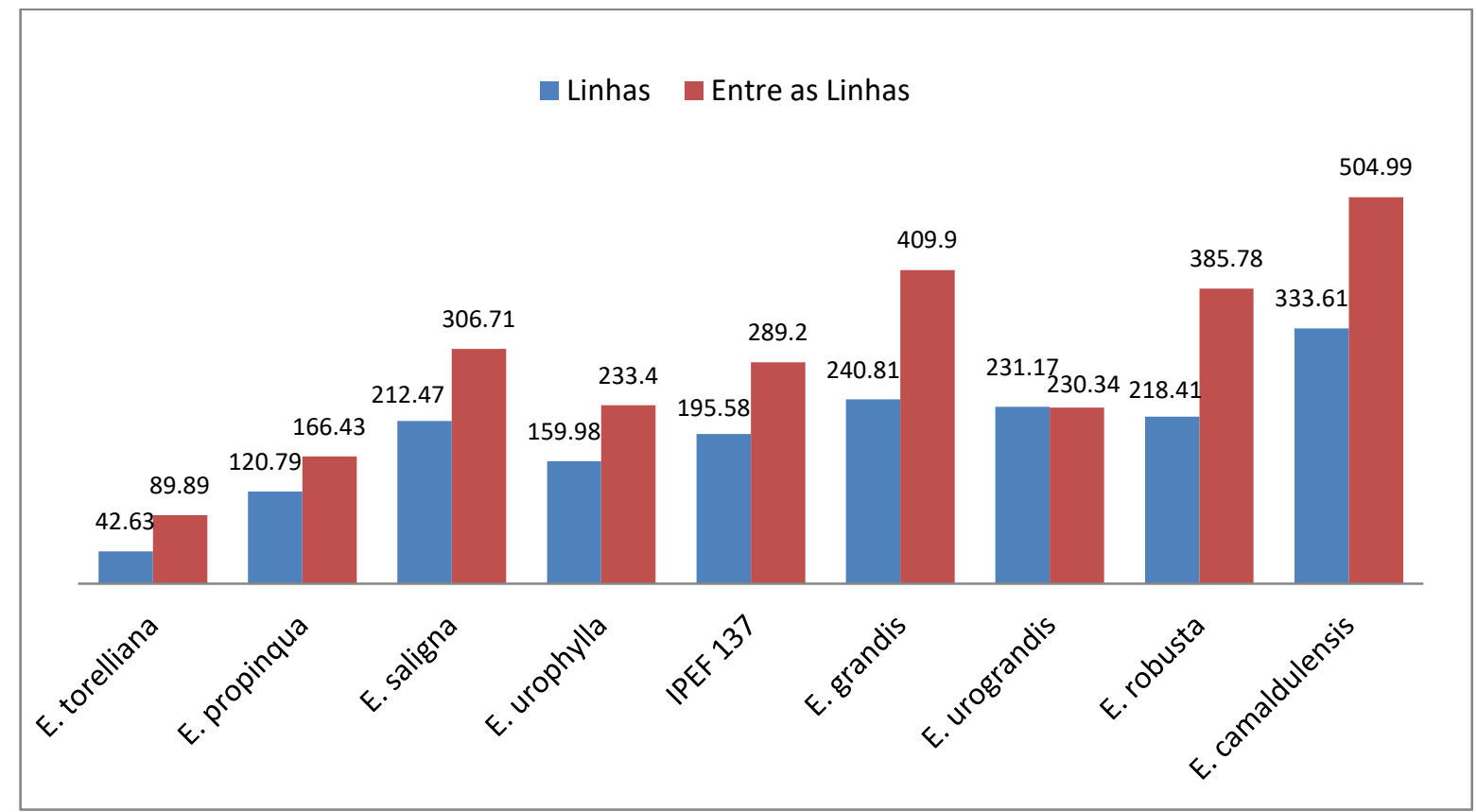

Figura 19. Radiação Fotossinteticamente Ativa $\left(\mu \mathrm{mol} \mathrm{m} \mathrm{m}^{-2} \mathrm{~s}^{-1}\right)$ nas espécies de eucalipto nas linhas e entrelinhas, no Bairro Água Bonita em Piracicaba-SP.

A diversidade de valores das variáveis IAF e TI resultam em diferentes valores de radiação disponível abaixo da floresta. Um exemplo de dois extremos dessas diferença são E. torelliana (maior IAF e TI) versus E. camaldulensis (menor IAF e TI) conforme pode ser observado na Figura 23. A característica de folhas lanceoladas longas e estreitas do $E$. camaldulensis permite a passagem de radiação para um crescimento vigoroso de plantas abaixo da floresta, e no $E$. torelliana com folhas lanceoladas curtas e largas permitem que pouca radiação passe através do dossel, refletindo em crescimento ralo e/ou inexistente. 


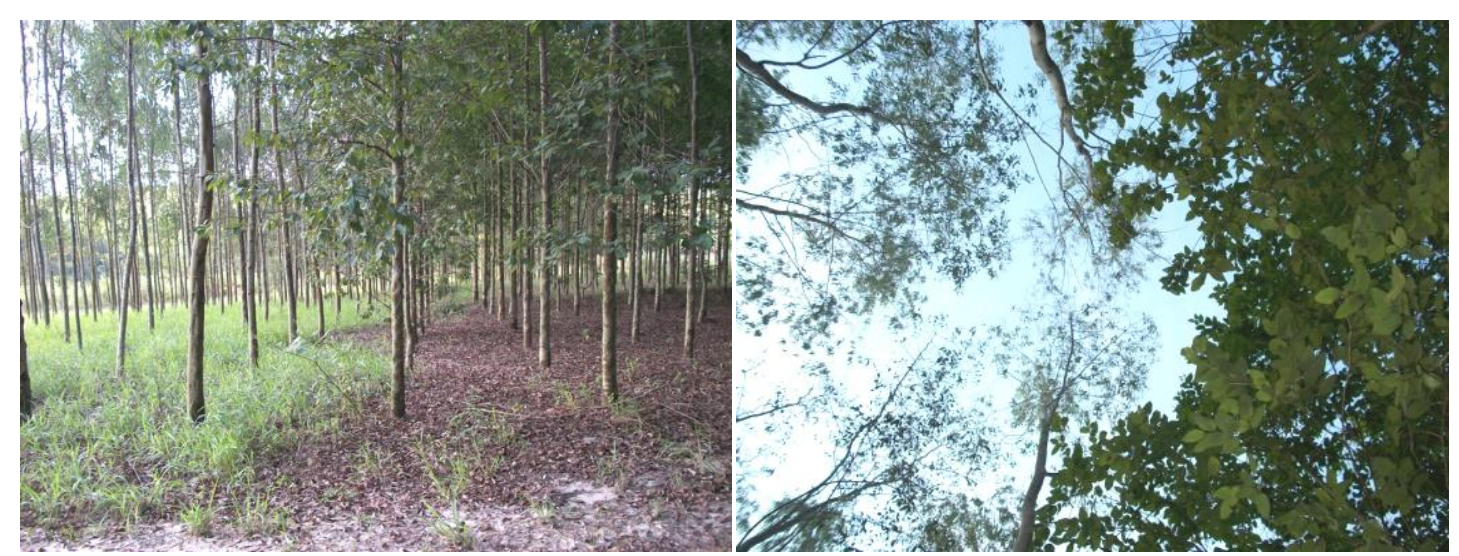

Figura 20. Diferença no crescimento de gramíneas abaixo das espécies em ambas as fotos a espécie E. camaldulensis (esquerda) e E. torelliana (direita) no Bairro Água Bonita em Piracicaba-SP.

Analisando o experimento de influência de espécies com 9 espécies de eucalipto, espaçamento $3 \times 2$ metros e 60 meses de idade, conclui-se que algumas das espécies têm um IAF, TI e RFA similares e outros bem distintos. A similaridade ou distinção entre as espécies advêm das suas características físicas e morfológicas, que ao interagirem com o meio resultando nas variáveis analisadas, sendo as características mais marcantes nesses casos foram: O formato da folha lanceolado, que apesar de característico varia desde o mais estreito e alongado do E. camaldulensis até o mais largo e curto do E. torelliana; $\mathrm{E}$ a densidade de copa que resulta da quantidade de galhos, quantidade de folhas por ramo e formato da copa.

Também foi possível observar que nas espécies o IAF está atrelado com a TI, quando a variável IAF é relativamente alta a TI também apresenta valor alto. 
Tabela 2. Resumo dos resultados dos valores médios do Índice de Área Foliar (IAF); da Taxa de Interceptação (TI) e da Radiação Fotossinteticamente Ativa (RFA) nas linhas e entrelinhas de plantios de 9 espécies de eucalipto com 60 meses de idade, espaçamento 3 x 2 m no Bairro Água Bonita em Piracicaba-SP.

\begin{tabular}{|c|c|c|c|c|c|}
\hline Tratamentos & $\begin{array}{c}\text { IAF }\left(\mathrm{m}^{2} \mathrm{~m}^{-2}\right) \\
*\end{array}$ & $\begin{array}{c}\text { TI nas linhas } \\
(\%)\end{array}$ & $\begin{array}{c}\text { TI nas } \\
\text { entrelinhas } \\
(\%)\end{array}$ & $\begin{array}{c}\text { RFA nas } \\
\text { linhas }(\mu \mathrm{mol} \\
\left.\mathrm{m}^{-2} \mathrm{~s}^{-1}\right) * *\end{array}$ & 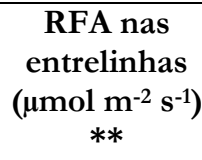 \\
\hline E. torelliana & $5,67 \mathrm{a}$ & $95,62 \mathrm{a}$ & $90,69 \mathrm{a}$ & $42,63 d$ & $89,89 \mathrm{~d}$ \\
\hline E. propinqua & $3,97 b$ & $87,15 \mathrm{ab}$ & $82,05 \mathrm{ab}$ & $120,79 \mathrm{~cd}$ & $166,43 \mathrm{~cd}$ \\
\hline E. saligna & $3,57 \mathrm{bc}$ & $80,01 b c$ & $70,99 \mathrm{bc}$ & $212,47 b c$ & $306,71 \mathrm{bc}$ \\
\hline E. urophylla & $3,36 \mathrm{bc}$ & $82,90 \mathrm{bc}$ & $74,91 \mathrm{bc}$ & $159,98 \mathrm{bc}$ & $233,40 \mathrm{~cd}$ \\
\hline IPEF 137 & $3,01 \mathrm{~cd}$ & $78,66 \mathrm{bcd}$ & $68,83 \mathrm{bcd}$ & $195,58 \mathrm{bc}$ & $289,20 \mathrm{bc}$ \\
\hline E. grandis & $2,45 \mathrm{de}$ & 74,00 cde & $55,97 \mathrm{de}$ & $240,81 \mathrm{ab}$ & $409,90 \mathrm{ab}$ \\
\hline $\begin{array}{l}\text { E. urophylla } \times E \text { E. } \\
\text { grandis }\end{array}$ & $2,07 \mathrm{e}$ & $66,69 \mathrm{e}$ & $60,79 \mathrm{cde}$ & $231,17 \mathrm{abc}$ & $230,34 \mathrm{~cd}$ \\
\hline E. robusta & $1,87 \mathrm{e}$ & $67,58 \mathrm{de}$ & $46,76 \mathrm{e}$ & $218,41 \mathrm{bc}$ & $385,78 \mathrm{ab}$ \\
\hline E. camaldulensis & $1,72 \mathrm{e}$ & $65,13 \mathrm{e}$ & $47,23 \mathrm{e}$ & $333,61 \mathrm{a}$ & $504,99 \mathrm{a}$ \\
\hline
\end{tabular}

Médias seguidas de letras iguais na mesma coluna não diferem pelo teste Tukey $(5 \%)$

*Valores de referência de IAF 2 a 4,5 $\mathrm{m}^{2} \mathrm{~m}^{-2}$ (Foelkel, 2005).

**Valores de RFA: RAZOÁVEL (entre 200 e $799 \mu \mathrm{mol} \mathrm{m}^{-2} \mathrm{~s}^{-1}$ ) (Williams, 1994). 


\subsection{Experimento de avaliação de desrama no Bairro Água Bonita, Piracicaba-SP:}

Após a realização da desrama espera-se uma diminuição nos valores de IAF e isso se confirmou na maioria dos casos com a exceção do $E$. grandis e $\mathrm{H} 15$ onde não houve diferença significativa, conforme observado na Figura 21. Nos casos das espécies VT 01 e $E$. urophylla que tinham o maior IAF, coincidentemente tiveram as maiores perdas de IAF depois da desrama. Porém, isso também ocorreu com a espécie E. citriodora que possuía o menor IAF antes da desrama e mesmo assim foi o terceiro com maior perda depois da desrama.

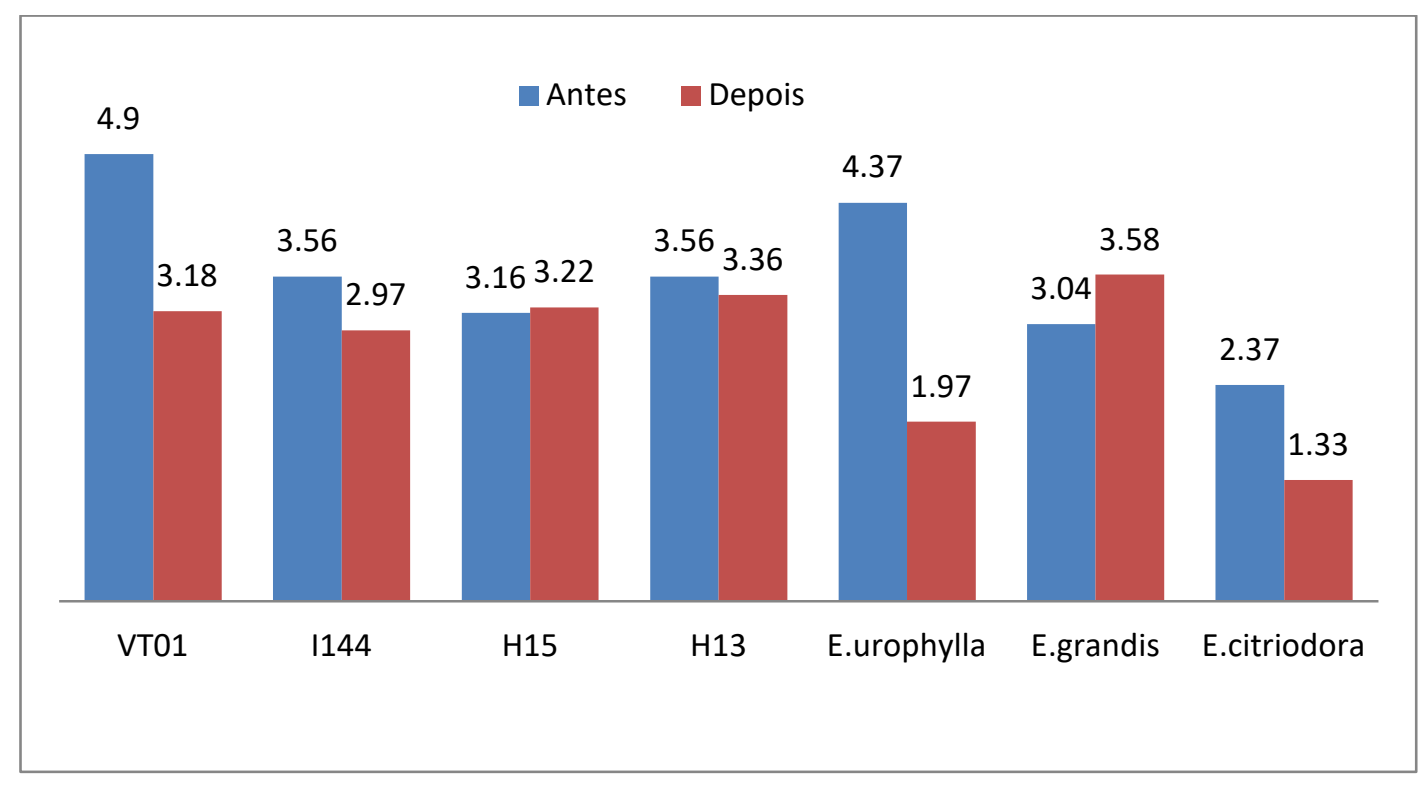

Figura 21. Índice de Área Foliar $\left(\mathrm{m}^{2} \mathrm{~m}^{-2}\right)$ nas espécies de eucalipto antes e depois da desrama, no Bairro Água Bonita em Piracicaba-SP.

Após a realização da desrama também é esperado um decréscimo nos valores TI na linha, o que foi confirmado na maioria dos casos e apresentado na Figura 22. As espécies H15 e E. grandis não houve diferença significativa. Nas entrelinhas a diminuição da taxa foi confirmada na maioria dos casos, porém, em geral essa queda foi menor do que as ocorridas nas linhas, não superando os 13\%. No caso das espécies H13 e E. grandis houve acréscimo na taxa, o que pode ser considerado adverso. 


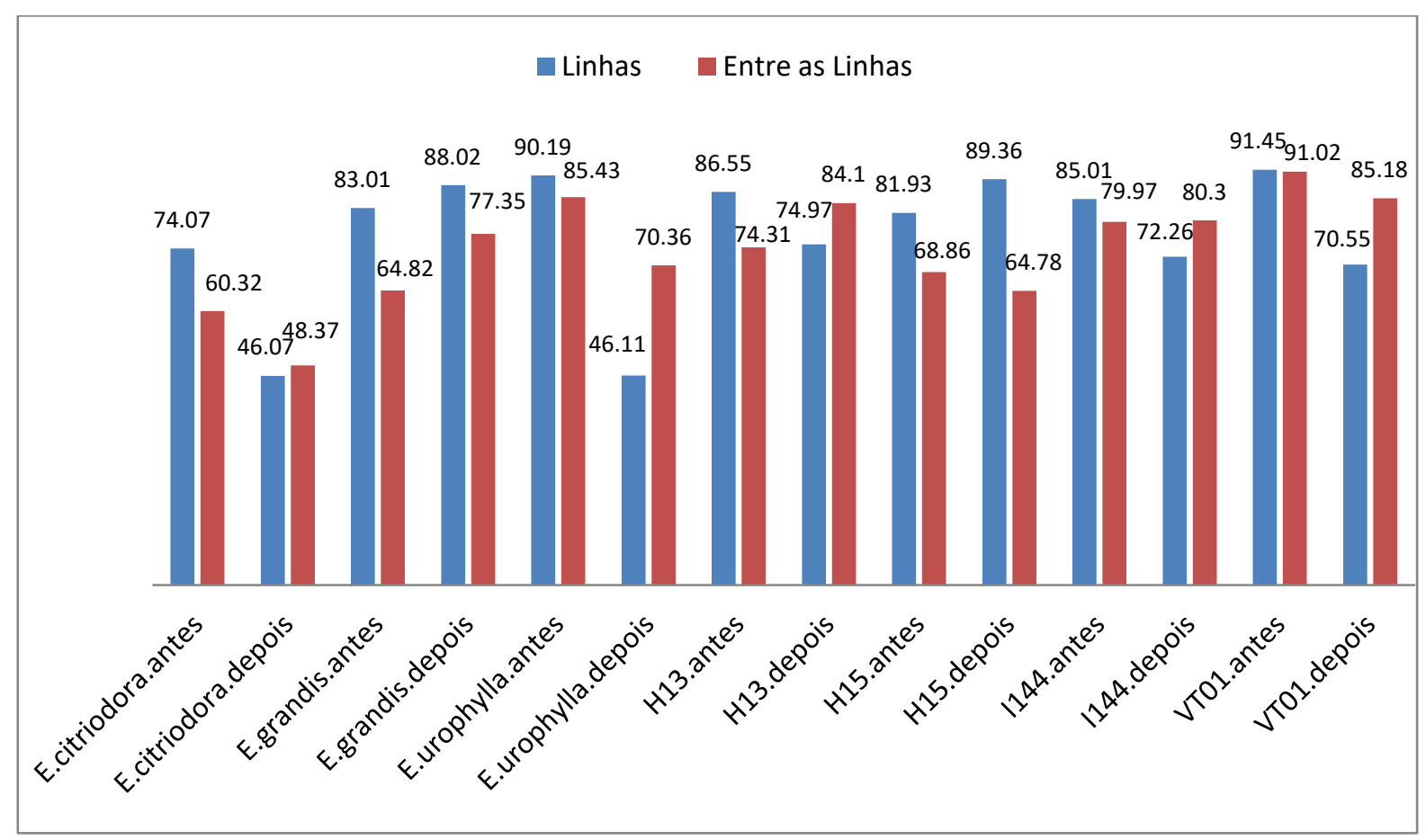

Figura 22. Taxa de Interceptação (\%) nas espécies de eucalipto antes e depois da desrama, no Bairro Água Bonita em Piracicaba-SP.

Na Figura 23 observa-se que a RFA nas linhas antes da desrama nas espécies $\mathrm{H} 15, E$. grandis e E. citriodora enquadraram-se na categoria MíNIMA (entre $100 \mu \mathrm{mol} \mathrm{m} \mathrm{m}^{-2} \mathrm{~s}^{-1}$ e $199 \mu \mathrm{mol} \mathrm{m} \mathrm{m}^{-2} \mathrm{~s}^{-1}$ ); as outras espécies H13, I144, VT 01 e E. urophylla na categoria INSUFICIENTE (menor que $99 \mathrm{\mu mol} \mathrm{m}^{-2} \mathrm{~s}^{-1}$ ). Depois da desrama nas espécies H13, I144, VT 01, E. urophylla e E. citriodora as mesmas enquadraram-se na categoria RAZOÁVEL (entre 200 e $799 \mu \mathrm{mol} \mathrm{m}^{-2} \mathrm{~s}^{-1}$ ); as espécies H15 e E. citriodora mantiveram-se na categoria MíNIMA (entre $100 \mu \mathrm{mol} \mathrm{m}^{-2} \mathrm{~s}^{-1}$ e $199 \mu \mathrm{mol} \mathrm{m}{ }^{-2} \mathrm{~s}^{-1}$ ).

A radiação nas linhas das espécies E. citriodora, E. urophylla e VT 01 foram as que sofreram maior alteração após a desrama. No comparativo de antes e depois da desrama era esperado um aumento na média de radiação após a desrama, e isso foi confirmado na maioria dos casos, na espécie H15 não houve diferença significativa.

Na Figura 23 observa-se que a RFA antes da desrama nas entrelinhas nas espécies H15 e E. grandis enquadraram-se na categoria RAZOÁVEL (entre 200 e $799 \mu \mathrm{mol} \mathrm{m}^{-}$ ${ }^{2} \mathrm{~s}^{-1}$ ); as espécies I 144, H 13 e E. citriodora na categoria MíNIMA (entre $100 \mu \mathrm{mol} \mathrm{m}{ }^{-2} \mathrm{~s}^{-1} \mathrm{e}$ $199 \mu \mathrm{mol} \mathrm{m}{ }^{-2} \mathrm{~s}^{-1}$ ); as espécies VT 01 e E. urophylla na categoria INSUFICIENTE (menor que 99 $\mu \mathrm{mol} \mathrm{m}^{-2} \mathrm{~s}^{-1}$ ). Depois da desrama nas entrelinhas nas espécies $\mathrm{H} 15, \mathrm{I} 144$ e E. grandis, $E$. urophylla e E. citriodora enquadraram-se na categoria RAZOÁVEL (entre 200 e $799 \mu \mathrm{mol} \mathrm{m}^{-2}$ 
$\mathrm{s}^{-1}$ ); as espécies H13 e VT 01 na categoria MíNIMA (entre $100 \mu \mathrm{mol} \mathrm{m}{ }^{-2} \mathrm{~s}^{-1}$ e $199 \mu \mathrm{mol} \mathrm{m} \mathrm{m}^{-2} \mathrm{~s}^{-}$ $\left.{ }^{1}\right)$, (Williams, 1994).

A radiação nas entrelinhas das espécies E. citriodora, e as espécies H15 e I144 foram as que sofreram maior alteração após a desrama. Também no comparativo de antes e depois da desrama nas entrelinhas era esperado um aumento na média de radiação após a desrama, e isso foi confirmado na maioria dos casos, a espécie E. grandis não houve diferença significativa.

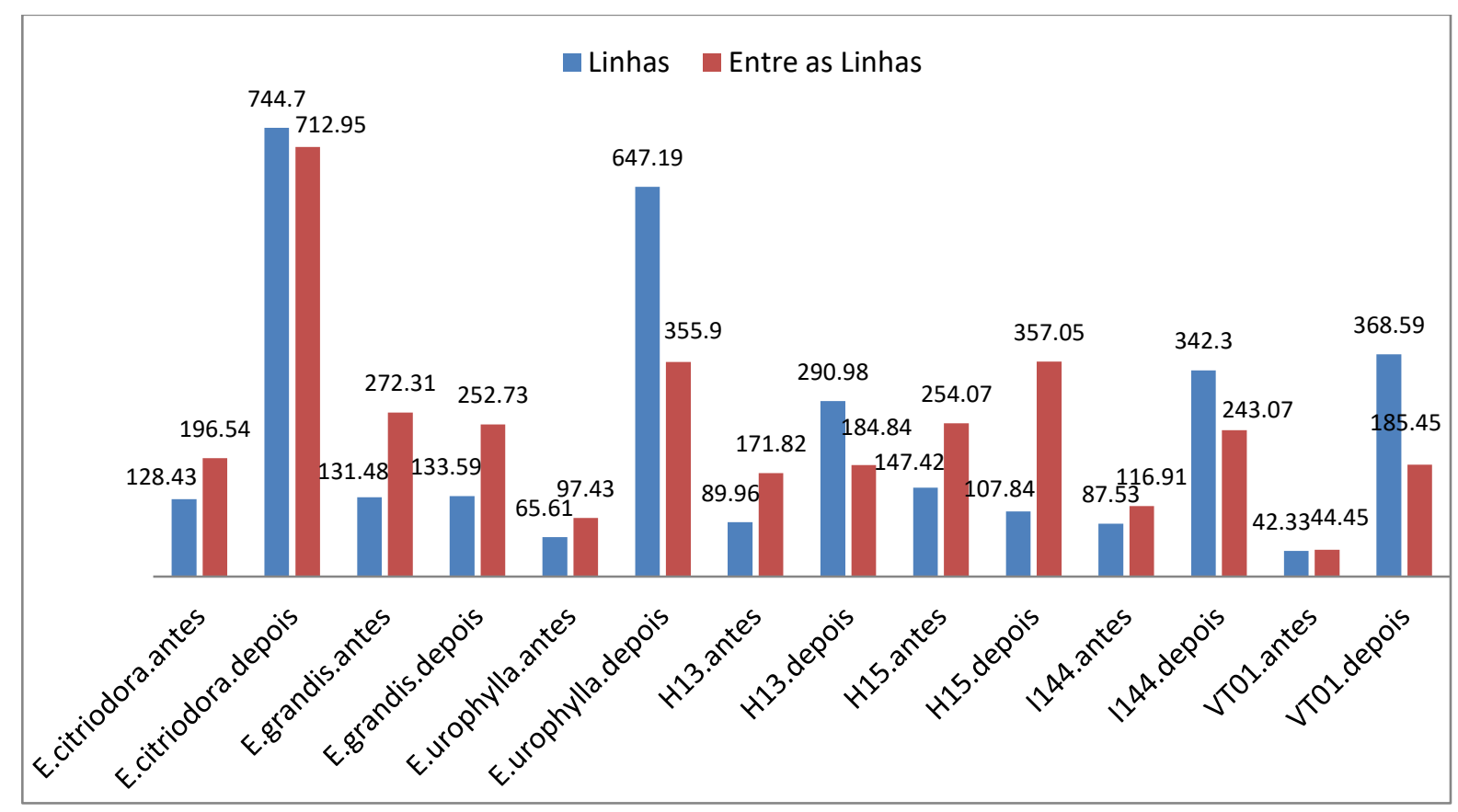

Figura 23. Radiação Fotossinteticamente Ativa $\left(\mu \mathrm{mol} \mathrm{m} \mathrm{m}^{-2} \mathrm{~s}^{-1}\right)$ nas espécies de eucalipto nas linhas e entrelinhas, antes e depois da desrama, no Bairro Água Bonita em Piracicaba-SP.

Através deste experimento, conclui-se que a desrama na maioria dos casos contribuiu para diminuir o IAF e a TI, e aumentar a RFA. Alguns casos foram considerados exceção uma vez que houve aumento no IAF e da TI e diminuição RFA após a desrama, sendo necessário maiores estudos para justificar esses fenômenos. Conclui-se também que antes da desrama nas linhas nenhum dos eucaliptos estudados apresentaram condições ideais para o desenvolvimento de plantas, já após a desrama as espécies H13, I144, VT01, E. urophylla e E. citriodora conseguiram alcançar os valores tidos como ideais. Nas entrelinhas, antes da desrama, as espécies H15 e E. grandis apresentaram condições ideais para o desenvolvimento de plantas e após a desrama, além das espécies H15 e E. grandis, as 
espécies I144, E. urophylla e E. citriodora também alcançaram valores de radiação dentro da categoria RAZOÁVEL.

Tabela 3. Resumo dos resultados do comparativo de antes de depois da desrama dos valores médios do Índice de Área Foliar (IAF); da Taxa de Interceptação (TI) e da Radiação Fotossinteticamente Ativa (RFA) na linha e entrelinhas de plantios de 7 espécies de eucalipto com 12 meses de idade, espaçamento 3 x 2 m no Bairro Água Bonita em Piracicaba-SP.

\begin{tabular}{cccccc}
\hline $\begin{array}{c}\text { Tratamentos (antes e } \\
\text { depois) }\end{array}$ & IAF $\left(\mathbf{m}^{2} \mathbf{~ m}^{-2}\right) *$ & $\begin{array}{c}\text { TI nas } \\
\text { linhas } \mathbf{~} \%)\end{array}$ & $\begin{array}{c}\text { TI nas } \\
\text { entrelinhas } \mathbf{( \% )})\end{array}$ & $\begin{array}{c}\text { RFA nas } \\
\text { linhas }(\boldsymbol{\mu m o l} \\
\left.\mathbf{m}^{-2} \mathbf{s}^{-1}\right)\end{array}$ & $\begin{array}{c}\text { RFA nas } \\
\text { entrelinhas } \\
\left(\boldsymbol{\mu} \mathbf{m o l}_{\mathbf{~ m}}^{-2} \mathbf{s}^{-1}\right)\end{array}$ \\
\hline VT01 antes & $4,90 \mathrm{a}$ & $91,45 \mathrm{a}$ & $91,02 \mathrm{a}$ & $42,33 \mathrm{~d}$ & $44,45 \mathrm{e}$ \\
E. urophylla antes & $4,37 \mathrm{ab}$ & $90,19 \mathrm{a}$ & $85,43 \mathrm{ab}$ & $65,61 \mathrm{~d}$ & $97,43 \mathrm{de}$ \\
E. grandis depois & $3,58 \mathrm{bc}$ & $88,02 \mathrm{ab}$ & $77,35 \mathrm{abcd}$ & $133,59 \mathrm{~d}$ & $252,73 \mathrm{bcd}$ \\
H13 antes & $3,56 \mathrm{bc}$ & $86,55 \mathrm{abc}$ & $74,31 \mathrm{abcd}$ & $89,96 \mathrm{~d}$ & $171,82 \mathrm{cde}$ \\
I144 antes & $3,56 \mathrm{bc}$ & $85,01 \mathrm{abcd}$ & $79,97 \mathrm{abc}$ & $87,53 \mathrm{~d}$ & $116,91 \mathrm{cde}$ \\
H13 depois & $3,36 \mathrm{c}$ & $74,97 \mathrm{bcde}$ & $84,10 \mathrm{ab}$ & $290,98 \mathrm{bc}$ & $184,84 \mathrm{bcde}$ \\
H15 depois & $3,22 \mathrm{~cd}$ & $89,36 \mathrm{a}$ & $64,78 \mathrm{cde}$ & $107,84 \mathrm{~d}$ & $357,05 \mathrm{~b}$ \\
VT01 depois & $3,18 \mathrm{~cd}$ & $70,55 \mathrm{e}$ & $85,18 \mathrm{ab}$ & $368,59 \mathrm{~b}$ & $185,45 \mathrm{bcde}$ \\
H15 antes & $3,16 \mathrm{~cd}$ & $81,93 \mathrm{abcde}$ & $68,86 \mathrm{bcd}$ & $147,42 \mathrm{~d}$ & $254,07 \mathrm{bcd}$ \\
E. grandis antes & $3,04 \mathrm{~cd}$ & $83,01 \mathrm{abcde}$ & $64,82 \mathrm{cde}$ & $131,48 \mathrm{~d}$ & $272,31 \mathrm{bc}$ \\
I144 depois & $2,97 \mathrm{~cd}$ & $72,26 \mathrm{de}$ & $80,30 \mathrm{abc}$ & $342,30 \mathrm{~b}$ & $243,07 \mathrm{bcd}$ \\
E. citriodora antes & $2,37 \mathrm{de}$ & $74,07 \mathrm{cde}$ & $60,32 \mathrm{de}$ & $128,43 \mathrm{~d}$ & $196,54 \mathrm{bcde}$ \\
E. urophylla depois & $1,97 \mathrm{ef}$ & $46,11 \mathrm{f}$ & $70,36 \mathrm{bcd}$ & $647,19 \mathrm{a}$ & $355,90 \mathrm{~b}$ \\
E. citriodora depois & $1,33 \mathrm{f}$ & $46,07 \mathrm{f}$ & $48,37 \mathrm{e}$ & $744,7 \mathrm{a}$ & $712,95 \mathrm{a}$ \\
\hline
\end{tabular}

Médias seguidas de letras iguais na mesma coluna não diferem pelo teste Tukey $(5 \%)$

*Valores de referência de IAF 2 a 4,5 $\mathrm{m}^{2} \mathrm{~m}^{-2}$ (Foelkel, 2005).

\subsection{Experimento de comparação entre intensidades de desbaste na EECFI, Itatinga-SP:}

A Tabela 4 refere-se à comparação de intensidade de desbaste nas variáveis IAF e TI, em que foi possível observar uma relação entre o aumento da intensidade com a diminuição dos valores de IAF e TI quando comparados 55\% x 85\% e 55\% x 70\%, porém, no caso de $70 \%$ x $85 \%$ não houve essa relação. A RFA nas três intensidades de desbaste nas linha e nas entrelinhas se enquadraram na categoria RAZOÁVEL (entre 200 e $799 \mu \mathrm{mol} \mathrm{m}{ }^{-2} \mathrm{~s}^{-}$ $\left.{ }^{1}\right)$, (Williams, 1994). 
Tabela 4. Comparação de intensidade de desbaste 55\%, 70\% e 85\% sobre os valores médios do Índice de Área Foliar (IAF); da Taxa de Interceptação (TI) e da Radiação Fotossinteticamente Ativa (RFA) nas linhas e entrelinhas de plantios de eucalipto E. grandis com 228 meses de idade, espaçamento original 3 × 2 m na EECF em Itatinga-SP.

\begin{tabular}{cccccc}
\hline $\begin{array}{c}\text { Intensidade de } \\
\text { desbaste }\end{array}$ & $\begin{array}{c}\text { IAF } \mathbf{( m}^{2} \mathbf{m}^{-} \\
\mathbf{2}) *\end{array}$ & $\begin{array}{c}\text { TI nas linhas } \\
\mathbf{( \% )}\end{array}$ & $\begin{array}{c}\text { TI nas } \\
\text { entrelinhas } \\
\mathbf{( \% )}\end{array}$ & $\begin{array}{c}\text { RFA nas } \\
\text { linhas }(\boldsymbol{\mu m o l} \\
\left.\mathbf{m}^{-2} \mathbf{s}^{-1}\right)\end{array}$ & $\begin{array}{c}\text { RFA nas } \\
\text { entrelinhas } \\
\left(\boldsymbol{\mu} \mathbf{m o l ~ m}^{-2} \mathbf{~ s}^{-1}\right)\end{array}$ \\
\hline $55 \%$ & $4,06 \mathrm{a}$ & $82,93 \mathrm{a}$ & $86,96 \mathrm{a}$ & $229,49 \mathrm{c}$ & $260,26 \mathrm{c}$ \\
$85 \%$ & $3,17 \mathrm{~b}$ & $77,26 \mathrm{~b}$ & $74,93 \mathrm{~b}$ & $346,75 \mathrm{~b}$ & $382,30 \mathrm{~b}$ \\
$70 \%$ & $3,07 \mathrm{c}$ & $67,74 \mathrm{c}$ & $70,44 \mathrm{~b}$ & $491,93 \mathrm{a}$ & $450,77 \mathrm{a}$ \\
\hline
\end{tabular}

Médias seguidas de letras iguais na mesma coluna não diferem pelo teste Tukey (5\%)

*Valores de referência de IAF 2 a 4,5 $\mathrm{m}^{2} \mathrm{~m}^{-2}$ (Foelkel, 2005).

A análise deste experimento afirma que o desbaste têm influencia sobre a alteração das variáveis IAF, TI e RFA e ainda, que com o desbaste seletivo criasse espaços aleatórios no talhão, o que influenciou nas variáveis; o melhor resultado foi na intensidade de desbaste de $70 \%$ pois apresentou o maior valor de RFA em relação ao de $85 \%$ e $55 \%$.

\subsection{Experimento de comparação entre espécies na EECFA, Anhembi-SP:}

$\mathrm{Na}$ Figura 24 observa-se que as espécies E. tereticornis, E. saligna, E. citriodora, E. microcoris, E. cloeziana, E. torelliodora e E. maculata apresentaram valores de IAF menores que o esperado para o eucalipto de 2 a $4,5 \mathrm{~m}^{2} \mathrm{~m}^{-2}$ (Foelkel, 2005). No caso das espécies E. cloeziana, E. torelliodora e E. maculata, durante o período de coleta, as árvores não chegavam a atingir $2 \mathrm{~m}$ de altura, não havendo contato entre as plantas, seja nas linhas ou nas entrelinhas; já as espécies E. torelliana, E. urophylla $\times$ E. grandis e E. brassiana apresentaram contato de ramos nas linhas e nas entrelinhas refletindo em IAF maiores. 


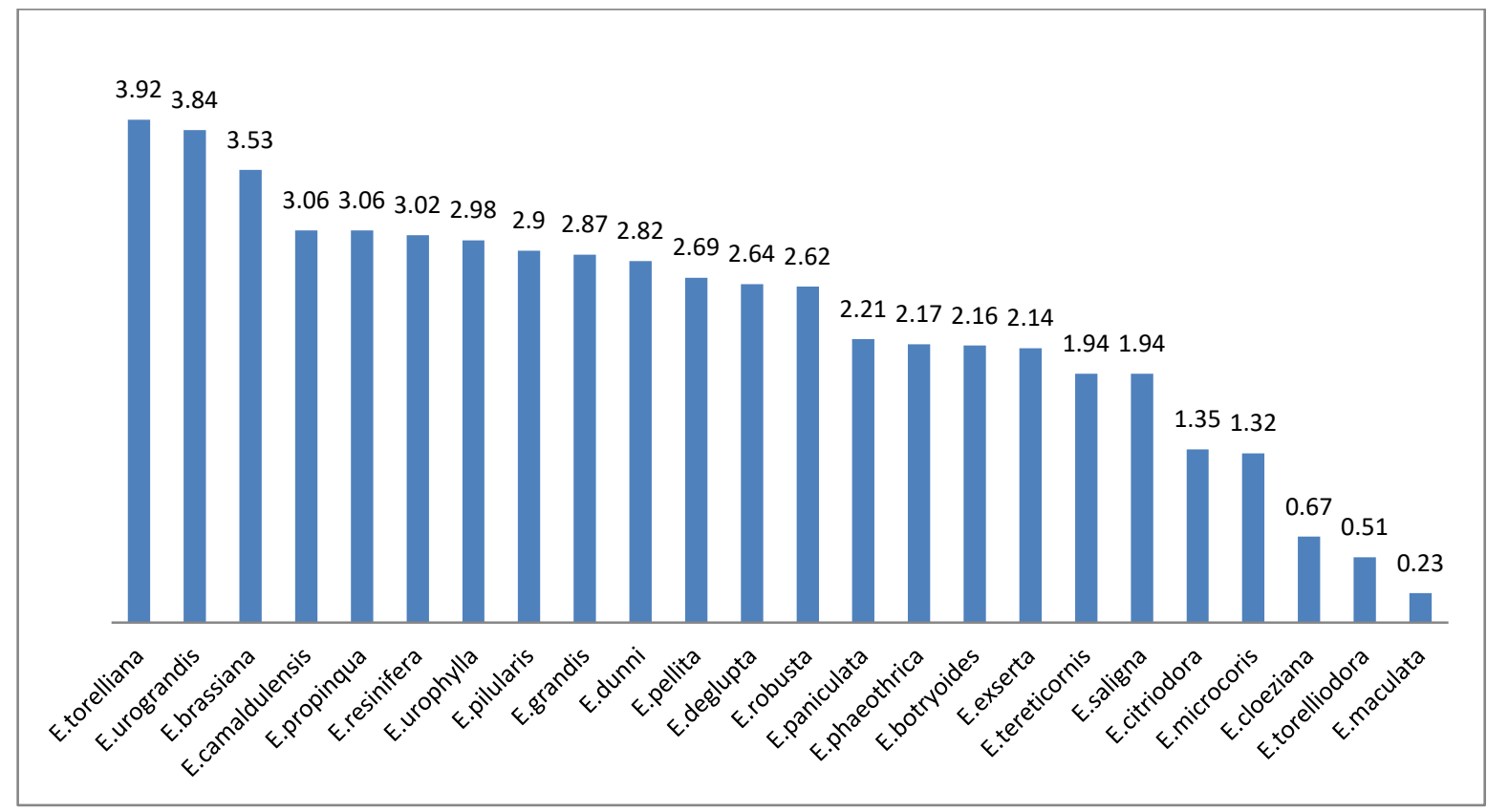

Figura 24. Índice de Área Foliar $\left(\mathrm{m}^{2} \mathrm{~m}^{-2}\right)$ nas espécies de eucalipto, na EECF em Anhembi-SP.

Os valores $\mathrm{Tl}$ apresentados na Figura 25 conseguiram expor a velocidade de desenvolvimento das espécies e a forma com que cada uma ocupa o espaço que lhe é oferecido, na maioria das espécies a TI na linha foi maior que nas entrelinhas, com exceção das espécies E. grandis, E. robusta, E.tereticornis, E. citriodora e E. microcorys. 


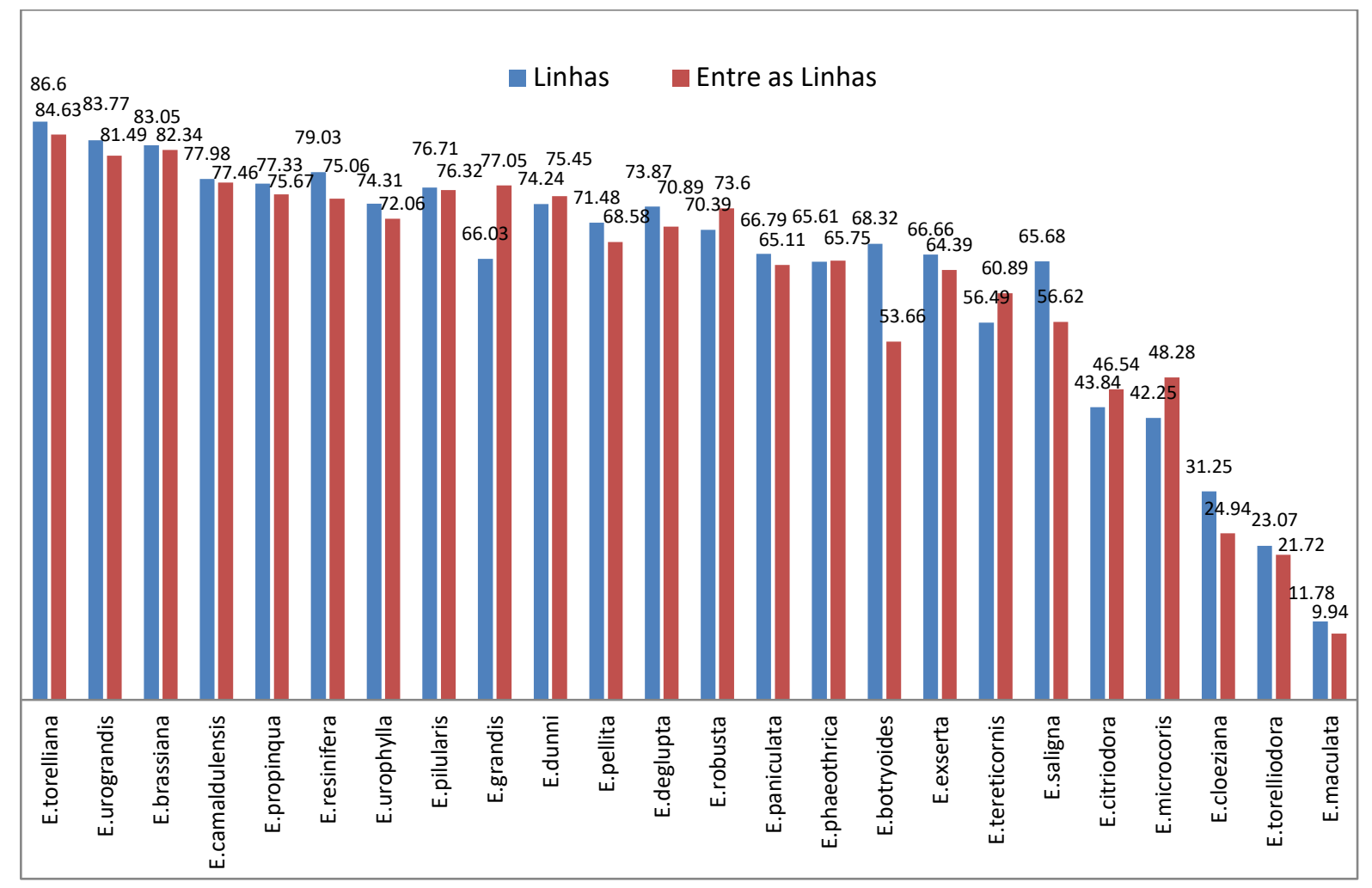

Figura 25. Taxa de Interceptação (\%) nas espécies de eucalipto, na EECF em Anhembi-SP.

Na Figura 26 observa-se que a RFA nas linhas das espécies $E$. maculata e $E$. torelliodora se enquadra na categoria IDEAL (acima de $800 \mu \mathrm{mol} \mathrm{m}^{-2} \mathrm{~s}^{-1}$ ); as espécies $E$. cloeziana, E. citriodora, E. pilularis, E. phaeothrica, E. microcorys, E. deglupta, E. paniculata, E. tereticornis, E. exserta, E. saligna, E. grandis, E. urophylla, E. urophylla $\times$ E. grandis, E. pellita, E. propinqua, E. resinifera, E. dunni e E. robusta, se enquadraram na categoria

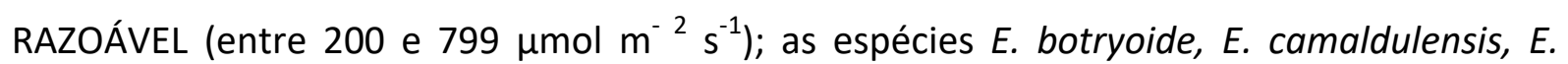
toreliana e E. brassiana na categoria MíNIMA (entre $100 \mu \mathrm{mol} \mathrm{m}^{-2} \mathrm{~s}^{-1} \mathrm{e} 199 \mu \mathrm{mol} \mathrm{m}^{-2} \mathrm{~s}^{-1}$ ).

Nas entrelinhas das espécies E. maculata, E. torelliodora e E. cloeziana se

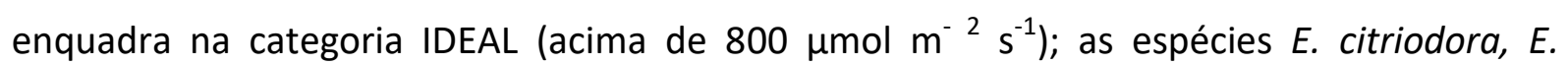
pilularis, E. phaeothrica, E. microcorys, E. deglupta, E. paniculata, E. tereticornis, E. exserta, E. saligna, E. botryoides, E. grandis, E. urophylla, E. urophylla x E. grandis (E. urograndis), E. pellita, E. propinqua, E. resinifera, E. dunni e E. robusta e E. camaldulensis se enquadraram

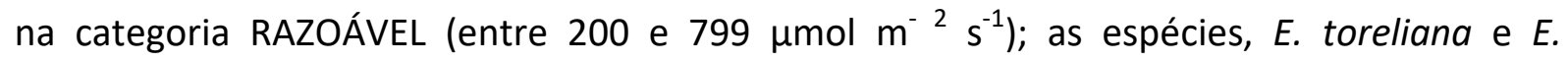
brassiana na categoria MíNIMA (entre $100 \mu \mathrm{mol} \mathrm{m}^{-2} \mathrm{~s}^{-1}$ e $199 \mu \mathrm{mol} \mathrm{m}^{-2} \mathrm{~s}^{-1}$ ), (Williams, 1994). 


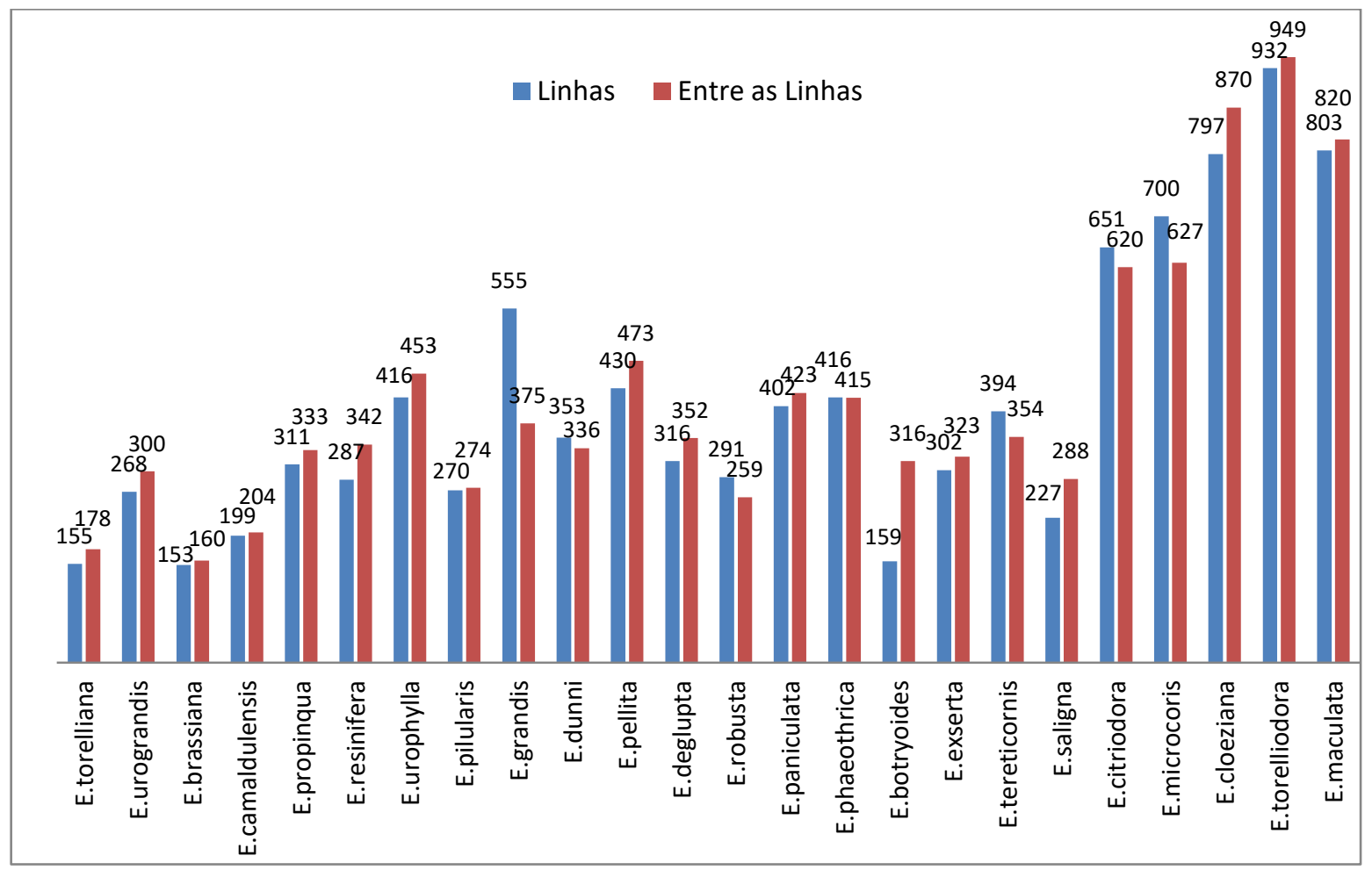

Figura 26. Radiação Fotossinteticamente Ativa $\left(\mu \mathrm{mol} \mathrm{m} \mathrm{m}^{-2} \mathrm{~s}^{-1}\right)$ nas espécies de eucalipto, na EECF em Anhembi-SP.

Diante dos resultados obtidos neste experimento, conclui-se que existem similaridades e distinções entre as espécies e a característica que mais afetou as variáveis estudadas foi a velocidade de crescimento inicial das espécies. Os E. torelliana, E. urophyllax E. grandis e E. brassiana possuíam um crescimento inicial rápido tanto horizontal na produção de ramos e folhas como vertical em altura das árvores, produzindo assim uma copa densa; diferentemente dos E. cloeziana, E. torelliodora e E. maculata que possuem um crescimento inicial lento, com altura e tamanho de copa reduzido.

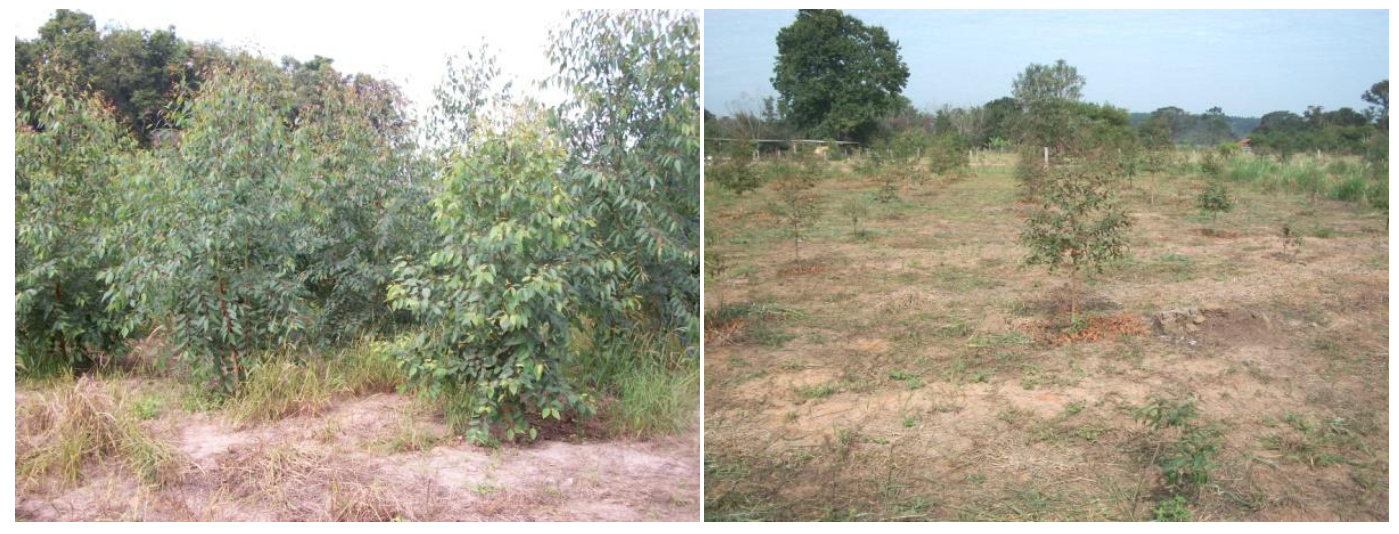

Figura 27. Diferença no crescimento inicial das espécies E. urophylla $\times$ E. grandis (esquerda) e E. cloeziana (direita) na EECF em Anhembi-SP. 
Tabela 5. Resumo dos resultados dos valores médios do Índice de Área Foliar (IAF); da Taxa de Interceptação (TI) e da Radiação Fotossinteticamente Ativa (RFA) nas linhas e entrelinhas de plantios de 24 espécies de eucalipto com 12 meses de idade, espaçamento 3 × 2 m na EECF em Anhembi-SP.

\begin{tabular}{|c|c|c|c|c|c|}
\hline Tratamentos & $\operatorname{IAF}\left(\mathrm{m}^{2} \mathrm{~m}^{-2}\right) *$ & $\begin{array}{c}\text { TI nas } \\
\text { linhas }(\%)\end{array}$ & $\begin{array}{c}\text { TI nas } \\
\text { entrelinhas } \\
\quad(\%)\end{array}$ & 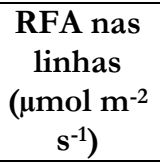 & $\begin{array}{c}\text { RFA nas } \\
\text { entrelinhas ( } \mu \mathrm{mol} \\
\left.\mathrm{m}^{-2} \mathrm{~s}^{-1}\right)\end{array}$ \\
\hline E. torelliana & $3,92 \mathrm{a}$ & $86,60 \mathrm{a}$ & $84,63 a$ & $155 \mathrm{~h}$ & $178 \mathrm{i}$ \\
\hline $\begin{array}{c}\text { E. urophylla } \times E \text {. } \\
\text { grandis }\end{array}$ & $3,84 a$ & $83,77 a$ & $81,49 \mathrm{ab}$ & $268 f g h$ & 300ghi \\
\hline E. brassiana & $3,53 \mathrm{ab}$ & $83,05 \mathrm{ab}$ & $82,34 a b$ & $153 \mathrm{~h}$ & $160 \mathrm{i}$ \\
\hline E. camaldulensis & $3,06 \mathrm{bc}$ & $77,98 \mathrm{abcd}$ & $77,46 \mathrm{abc}$ & $199 \mathrm{gh}$ & 204hi \\
\hline E. propinqua & $3,06 \mathrm{bc}$ & 77,33abcd & $75,67 \mathrm{abc}$ & 311efgh & 333fghi \\
\hline E. resinifera & $3,02 \mathrm{bc}$ & $79,03 \mathrm{abc}$ & $75,06 \mathrm{abc}$ & 287efgh & 342efghi \\
\hline E. urophylla & $2,98 \mathrm{bc}$ & 74,31 abcd & $72,06 \mathrm{bcd}$ & 416def & 453def \\
\hline E. pilularis & $2,90 \mathrm{bcd}$ & 76,71abcd & $76,32 \mathrm{abc}$ & $270 \mathrm{efgh}$ & 274ghi \\
\hline E. grandis & $2,87 \mathrm{bcd}$ & $66,03 \mathrm{de}$ & $77,05 \mathrm{abc}$ & $555 \mathrm{~cd}$ & 375 efgh \\
\hline E. dunni & $2,82 \mathrm{bcd}$ & $74,24 \mathrm{abcd}$ & $75,45 \mathrm{abc}$ & 353 efg & 336efghi \\
\hline E. pellita & $2,69 \mathrm{~cd}$ & $71,48 \mathrm{bcd}$ & $68,58 \mathrm{cde}$ & 430de & $473 \mathrm{cde}$ \\
\hline E. deglupta & $2,64 \mathrm{cde}$ & $73,87 \mathrm{abcd}$ & $70,89 \mathrm{bcde}$ & 316efgh & 352efghi \\
\hline E. robusta & $2,62 \mathrm{cde}$ & $70,39 \mathrm{bcd}$ & $73,60 \mathrm{abc}$ & 291efgh & 259ghi \\
\hline E. paniculata & 2,21de & $66,79 \mathrm{cde}$ & $65,11 \mathrm{cdef}$ & 402defg & 423defg \\
\hline E. phaeothrica & 2,17def & $65,61 \mathrm{de}$ & $65,75 \mathrm{cdef}$ & 416def & $415 \mathrm{efg}$ \\
\hline E. botryoides & 2,16defg & $68,32 \mathrm{bcde}$ & $53,66 \mathrm{fg}$ & $159 \mathrm{~h}$ & 316fghi \\
\hline E. exserta & 2,14defg & $66,66 \mathrm{cde}$ & $64,39 \mathrm{cdef}$ & 302efgh & 323fghi \\
\hline E. tereticornis & $1,94 \mathrm{efg}$ & $56,49 \mathrm{ef}$ & $60,89 \mathrm{defg}$ & 394defg & 354efghi \\
\hline E. saligna & $1,94 \mathrm{efg}$ & $65,68 \mathrm{de}$ & $56,62 \mathrm{efg}$ & $227 \mathrm{fgh}$ & 288ghi \\
\hline E. citriodora & 1,35fgh & $43,84 \mathrm{fg}$ & $46,54 \mathrm{~g}$ & $651 \mathrm{bc}$ & $620 \mathrm{~cd}$ \\
\hline E. microcoris & 1,32gh & $42,25 \mathrm{fg}$ & $48,28 \mathrm{~g}$ & $700 \mathrm{bc}$ & $627 \mathrm{bc}$ \\
\hline E. cloeziana & 0,67hi & $31,25 \mathrm{gh}$ & $24,94 \mathrm{~h}$ & $797 \mathrm{ab}$ & $870 \mathrm{a}$ \\
\hline E. torelliodora & $0,51 \mathrm{hi}$ & $23,07 \mathrm{hi}$ & 21,72hi & $932 \mathrm{a}$ & $949 \mathrm{a}$ \\
\hline E. maculata & $0,23 \mathrm{i}$ & $11,78 \mathrm{i}$ & $9,94 \mathrm{i}$ & $803 \mathrm{ab}$ & $820 \mathrm{ab}$ \\
\hline
\end{tabular}

Médias seguidas de letras iguais na mesma coluna não diferem pelo teste Tukey $(5 \%)$

*Valores de referência de IAF 2 a 4,5 $\mathrm{m}^{2} \mathrm{~m}^{-2}$ (Foelkel, 2005). 


\section{CONCLUSÕES}

Este trabalho teve como contribuição explicitar as diferenças entre as espécies de eucalipto pelo Índice de Área Foliar e a Taxa de Interceptação, ambas específicas para cada uma delas, como consequência dessas variáveis cada espécie apresenta diferentes quantidades de Radiação Fotossinteticamente Ativa disponível para as plantas sob os plantios. Além disso, através desse estudo conseguimos quantificar o ganho de Radiação Fotossinteticamente Ativa após a desrama, contribuindo para reforçar a utilização dessa prática em Sistemas Agroflorestais; também contribuiu para avaliar a consequência da realização de diferentes desbastes em plantios de eucalipto com mais idade sobre a RFA.

Podemos concluir com esse trabalho que as espécies de eucalipto que poderiam ser sugeridas para compor os Sistemas Agroflorestais são: E. camaldulensis, E. robusta, E. grandis, E. urophylla x E. grandis e E. saligna, pois, apresentaram condições razoáveis de RFA tanto aos 12 meses como aos 60 meses de idade. Porém, somente as espécies E. maculata, E. torelliodora e E. cloeziana com 12 meses apresentaram condições ideais de RFA.

Conclui-se também que espécies com valores de IAF e TI maiores, resultam numa menor quantidade de RFA disponível, pois, essas espécies tem a capacidade de interceptar maior quantidade de Radiação, portanto, devem ser evitadas em Sistemas Agroflorestais. No entanto, se escolhidas para o uso desde o plantio, um estudo prévio a fim de avaliar a quantidade de RFA deverá ser realizado. No caso de plantios já existentes e com pretensão de transformá-lo em Sistemas Agroflorestais, as práticas de desrama e desbaste deverão ser feitas em virtude de criar condições de RFA suficientes para o desenvolvimento da vegetação sob o plantio de eucalipto.

Quanto ao método de cálculo pela Lei de Lambert-Beer conclui-se que é uma forma ágil, indireta e não destrutiva de se obter o IAF e que na maioria dos cálculos realizados neste trabalho os valores de IAF apresentaram-se dentro da faixa de referência específica para o eucalipto de 2 a $4,5 \mathrm{~m}^{2} \mathrm{~m}^{-2}$. Porém, existe a necessidade de um estudo para obter os diferentes valores de coeficiente de extinção da luz para as diferentes espécies de eucalipto, assim o cálculo do Índice de Área Foliar pela Lei de Lambert-Beer se torna mais acurado. 
Conclui-se ainda que o estudo da $\mathrm{Tl}$ é importante para determinar o quanto de radiação disponível é interceptada pela copa das árvores do eucalipto e o quanto desta radiação resta para o crescimento de plantas abaixo da floresta, refletindo diretamente nos valores de RFA.

Diante de todas as avaliações realizadas, conclui-se que para aperfeiçoar Sistemas Agroflorestais é importante que no manejo florestal escolham-se as espécies com melhores características, além de realizar as práticas silviculturais de desrama e desbaste. 


\section{REFERÊNCIAS}

Abouziena HF, Abd El Wahed MS (2013) Production Capability of Wheat Cultivars under Low Light Intensity (Date Palm Shade) Conditions and Some Bioregulators. Journal of Applied Sciences $\quad$ 9(8): 5178.2 Disponível em: <http://www.aensiweb.com/old/jasr/jasr/2013/5176-5188.pdf>. Acesso em: 15 set. 2016.

Angeli A, Barrichelo, LEG, Müller PH (2005) Indicações para a escolha de espécies de Eucaliptus. Instituto de Pesquisas Florestais (IPEF). Disponível em: <http://www.ipef.br/identificacao/eucalyptus/indicacoes.asp>. Acessado em: 29 set. 2016.

Angelocci, LR, Vila Nova NA, Coelho Filho MA, Marin FR (2004) Measurements of net radiation absorbed by isolated acid lime trees (Citrus latifolia Tanaka) Journal of Horticultural Science \& Biotechnology 79 (5): 699-703. Disponível em: <http://ainfo.cnptia.embrapa.br/digital/bitstream/item/120659/1/1381.PDF>. Acessado em: 29 set. 2016.

Assis FN, Mendez MEG (1989) Relação entre Radiação Fotossintéticamente Ativa e Radiação Global. Pesquisa Agropecuária brasileira, julho 24(7): 800.

Baumgartner A (1956) Untersuchchungen uber den Warmer - und Wasserhausshalt eines jungen Waldes. Deut. Wtterdienstes Ber. 5 : 4-53. Translation 3760 by Dr. E. Pincher, Victoria, Australia. 116, mimeograph.

Bernardes MS (1987) Fotossíntese no dossel das plantas cultivadas. In: Castro P.; Ferreira SO; Yamada T; Ecofisiologia da produção agrícola. Piracicaba: Potafos. 13-48.

Borges JS, (2009) Parametrização, calibração e validação do modelo 3-PG para eucalipto na região do cerrado de Minas Gerais. Dissertação de Mestrado, Viçosa-MG, 6-44.

Caron BO, (2003) Influência da temperatura do ar e radiação solar no acúmulo de fitomassa da alface. Revista Brasileira de Agrometeorologia, Santa Maria, 11(2):275-283.

Caron BO, Lamego FP, Souza VQ, Costa EC, Eloy E, Behling A, Trevisan R (2012) Interceptação da radiação luminosa pelo dossel de espécies florestais e sua relação com o manejo das plantas daninhas. Ciência Rural, 42(1): 75-82. Disponível em: <http://www.scielo.br/scielo.php?script=sci_arttext\&pid=S0103-

84782012000100013\&lng=en\&nrm=iso>. Acesso 29 set. 2016. 
Chapman SR, Carter LP (1976) Crop Production: Principles and Practices. San Francisco: WH Freeman and Company, 146-163.

CIB (2008) Conselho de Informações sobre Biotecnologia. Guia do Eucalipto: Oportunidades para um Desenvolvimento Sustentável. Disponível em: http://cib.org.br/wpcontent/uploads/2011/10/Guia_do_Eucalipto_junho_2008.pdf. Acessado em: 07 mar. 2017.

Cromer RN (1995) Environmental Limitations to Growth of Plantation Eucalipts. The Role of Eucalypts and Other Fast Growing Species : Proceedings of the Joint Australian/Japanese Workshop Held in Australia, 27-36.

Czarnowski M, Slomka J (1959) Some remarks on the percolation of light through the forest canopy. Ecology 40: 312-315.

Eloy E, Caron BO, Behling A, Elli EF, Gean CM (2012) Influência do espaçamento na interceptação de radiação do dossel vegetativo de espécies arbóreas. Enciclopédia Biosfera, Centro Científico Conhecer - Goiânia, v.8(14): 685. Disponível em: <http://docplayer.com.br/2552459-Influencia-do-espacamento-na-interceptacao-deradiacao-do-dossel-vegetativo-de-especies-arboreas.html>. Acesso em: 15 set. 2016.

EMBRAPA (2010) Empresa Brasileira de Pesquisa Agropecuária. Cultivo do Milho: Clima e Solo. Disponível em: http://www.cnpms.embrapa.br/publicacoes/milho_6_ed/climaesolo.htm>. Acesso em: 09 mar. 2017.

Foelkel C (2005) Minerais e nutrientes das árvores dos eucaliptos: Aspectos ambientais, fisiológicos, silviculturais e industriais acerca dos elementos inorgânicos presentes nas árvores. Eucalyptus Newsletter, n. 2, out.

Fontan, ICI (2007) Dinâmica de copa e crescimento de clones de eucalipto submetidos a desramaem sistema agroflorestal. Dissertação de mestrado. Viçosa - MG, 1: 15.

Frisina VA, Gomes EN, Pasqual PH, Escobedo JF (1998) Estimativa da Radiação Fotossinteticamente Ativa (PAR) em função do Índice de Claridade (Kt). Congresso Brasileiro de Meteorologia, Edição X. Brasília. Disponível em: <http://www.cbmet.com/cbm-files/13-6e2606c16249ca60fc051bf1d231f317.pdf>. Acesso em: 02 mar. 2017. 
Gazarini LC, Araujo MC, Borralho N, Pereira JS (1990) Plant area index in Eucalyptus globulus plantations determined indirectly by a light interception method. Tree Physiology, 7: 107113.

Holmes MG, Klein W H, Sager JC (1985) Photons, flux, and some light on philology. Hort. Sci. 20: 29-31.

IBGE (2014) Instituto Brasileiro de Geografia e Estatística. Produção da Extração Vegetal e da Silvicultura. Disponível em: $<$ http://www.sidra.ibge.gov.br/bda/tabela/protabl.asp?c=5930\&z=p\&o=31\&i=P>. Acesso em: 29 set. 2016.

Jankowsky IP, Santos GRV, Andrade, A (2000) Secagem da madeira serrada de eucalipto. Actas de XV Jornadas Forestales de Entre Rios. Concordia. 2:1-13.

Jarvis PG, Leverenz JW (1983) Productivity of temperate, deciduous and evergreen forests. 233-280. In Large O L, Nobel PS, Osmond CB, Ziegler H Ecosystem processes: mineral cycling, productivity, and man's influence. Volume $12 \mathrm{D}$ in Physiological plant ecology: new series. Springer-Verlag, New York, USA.

Larcher W (2004) Ecofisiologia Vegetal: O ambiente das plantas. Tradução de Carlos Henrique Britto de Assis Prado. Revisão de Carlos Henrique Britto de Assis Prado \& Augusto Cesar Franco. 3 ed. São Carlos: RiMa, 2004. 518p.

Linder S (1985) Potentail and actual production in Australian forest stands. In Research for Forest Management, eds. Landsberg, J.J. \& Parson, W. Melbourne 11-51.

Liu J, Li S, Liang H, Jiang C, Wang B, Ma J (2007) Study on the Features of the Photosynthetic Active Radiation (PAR) with Experimentations and Measurements. Jornal of Natural Resources. Disponível em: <http://en.cnki.com.cn/Article_en/CJFDTotalZRZX200705002.htm>. Acesso em: 15 set. 2016.

Lopes MC, Andrade I, Pedroso V, Martins S (2004) Modelos empírico para estimativa da área foliar da videira na casta Jaen. Ciência e Tecnologia Vitivinicultura, 19(2): 61-75. Martini AJ (2004) O plantador de eucaliptos: A questão da preservação florestal no Brasil e o resgate documental do legado de Edmundo Navarro de Andrade. Tese de mestrado. 3108. Disponível em:<http://www.ipef.br/servicos/teses/arquivos/martini,aj.pdf $>$. Acesso em: 29 set. 2016. 
McCree KJ (1981) Photosynthetically active radiation. In Encyclopedia of Plant Physiology, New Series, Vol. 12A, Large O L, Nobel PS, Osmond CB, Ziegler, eds., Springer, Berlin, 4155.

Moraes L, Santos LK, Wisser TZ, Krupek RA (2013) Avaliação da área foliar a partir de medidas lineares simples de cinco espécies vegetais sob diferentes condições de luminosidade. Revista Brasileira de Biociencias, Porto Alegre, 11(4): 381. Disponível em: <http://www.ufrgs.br/seerbio/ojs/index.php/rbb/article/viewFile/2413/1221>. Acesso em: 15 set. 2016.

Nackaerts K, Coppin P, Muys B, Hermy M (2000) Sampling methodology for LAI measurements with LAI-2000 in small forest stands. Agric. For. Meteorol, 101(4): 247250.

Oliveira TK (2005) Sistema agrossilvipastoril com eucalipto e braquiária sob diferentes arranjos estruturais em área de Cerrado. Tese de Doutorado .Lavras: UFLA, 45-64-117.

Paiva SEA, Isaias RMD, Aguiar Vale FH, Queiroz CGD (2003). The influence of light intensity on anatomical structure and pigment contents of Tradescantia pallida (Rose) Hunt. cv. purpurea boom (Commelinaceae) leaves. Braz .Arch. Biol. Techn., 46: 617-624.

Passos CAM, Fernandes EN, Couto L (1992) Plantio consorciado de Eucalyptus grandis com milho no Vale do Rio Doce, Minas Gerais. In: ENCONTRO BRASILEIRO DE ECONOMIA E PLANEJAMENTO FLORESTAL, 2., 1991, Curitiba. Anais. Colombo: EMBRAPA-CNPF, 1:409421.

Pilau, F. G (2005) Saldo de radiação da copa de laranjeira num pomar e de renques de cafeeiros: medidas e estimativas. Tese de Doutorado, ESALQ Piracicaba, 92.

Queiroz RJS (2013) Estimativa do Índice de Área Foliar em Povoamentos de Pinheiro Bravo recorrendo a Inventário Florestal, Detecção Remota e Sistema de Informação Geográfica. Tese de Mestrado. Escola Superior Agrária de Ponte de Lima, 10-13. Disponível em: <http://repositorio.ipvc.pt/bitstream/123456789/1162/1/Rogerio_Queiros_10450.pdf>. Acesso em: 15 set. 2016.

Reifsnyder WE, Lull HW (1965) Radiant Energy in Relation to Forests. U.S. Department of Agriculture, Forest Service, Technical Bulletin 1344: 21-77.

Sanches L, Reis de Andrade N, Nogueira JS, Biudes MS, Vourlitis GL (2008) Índice de área foliar em floresta de transição amazônia cerrado em diferentes médotos de estimativa. Ciência e Natura, UFSM, 30(1): 57 - 69. 
Sands PJ, Landsberg JJ (2002) Parameterization of 3-PG for plantation grown Eucalyptus globulus. Forest Ecology and Management, 163:273-292.

Schreiner HG (1989) Culturas intercalares de soja em reflorestamentos de eucaliptos no Sul Sudeste do Brasil. Boletim de Pesquisa Florestal, Colombo, 18/19(jun./dez):1-10.

Schreiner HG, Baggio AJ (1989) Sistemas agroflorestais no Sul - Sudeste do Brasil. In: TALLER SOBRE DISENO ESTADISTICO Y EVALUACION ECONOMICA DE SISTEMAS AGROFORESTALES, Curitiba. Apuntes. Curitiba: EMBRAPA-CNPF; [Roma]: FAO, 45-73.

Schreiner HG, Balloni EA (1989) Consórcio das culturas de feijão (Phaseolus vulgaris L.) e eucalipto (Eucalyptus grandis W. Hill ex Maiden) no Sudeste do Brasil. Boletim de Pesquisa Florestal, Colombo, jun. 12:83-104.

Stape JL, Martini EL (1992) Plantio consorciado de Eucalyptus e arroz na região de Itararé-SP. In: ENCONTRO BRASILEIRO DE ECONOMIA E PLANEJAMENTO FLORESTAL, 2., 1991, Curitiba. Anais. Colombo: EMBRAPA-CNPF, 1:155-169.

Taiz L, Zeiger E, Møller IM, Murphy A (2015) Plant physiology and development, Topic 9.1: Working with Light. Disponível em: <http://6e.plantphys.net/topic09.01.html>. Acesso em: 15 set. 2016.

Valverde RS, Soares NS, Silva ML, Jacovine LAG, Neiva SA (2005) Mercado da madeira de eucalipto no Brasil. Revista da Madeira - REMADE, e. 88, março. Disponível em: <http://www.remade.com.br/br/revistadamadeira_materia.php?num=704\&>. Acesso em: 29 set. 2016.

Vergara BS (1978) Crop response to light variations. In: Gupta US, ed. Crop Physiology. New Delhi: Oxford \& IB Publishing Co, 137-156.

Wang YP, (2001) Modelling radiation absorption by plant canopies. NEE WORKSHOP PROCEEDINGS: 18-20.

Welles JM, Cohen S (1996) Canopy structure measurement by gap fraction analysis using commercial instrumentation. Journal of Experimental Botany, 47: 1335-1347.

Williams, P.H. 1994 Wisconsin Fast Plants, Seeing the Light: When growing Fast Plants, the more light the better. Disponivel em: $<$ http://www.fastplants.org/pdf/activities/seeing_the_light.pdf $>$. Acesso em: 15 set. 2016. 
Zervoudakis G, Salahas G, Kaspiris G, Konstantopoulou E (2012) Influence of light intensity on growth and physiological characteristics of common sage (Salvia officinalis L.). Arch. Biol. Technol., 55(1): 89-95.

Zhang S, Ma K, Chen L (2003) Response of photosynthetic plasticity of Paeonia suffruticosa to changed light environments. Environ. Exper. Bot., 49: 121-133z. 